\title{
Variación temporal del fitoplancton entre 1993 y 1998 en una estación fija del seno Aysén, Chile ( $\left(5^{\circ} 26^{\prime} \mathrm{S} 73^{\circ} 00^{\prime} \mathrm{W}\right)$
}

\author{
Temporal change of the phytoplankton between 1993 and 1998 in a fixed station inside Aysén fjord, \\ Chile $\left(45^{\circ} 26^{\prime} \mathrm{S} 73^{\circ} 00^{\prime} \mathrm{W}\right)$
}

\author{
David Cassis, Pablo Muñoz y Sergio Avaria \\ Universidad de Valparaíso, Facultad de Ciencias del Mar, Casilla 13-D, Viña del Mar, Chile. \\ dcassis@eos.ubc.ca
}

Resumen.- Se da a conocer la distribución temporal del fitoplancton en una estación fija en la cabeza del seno Aysén

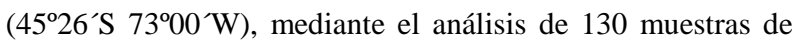
red obtenidas quincenalmente entre febrero de 1993 y junio de 1998.

El análisis de las muestras permitió identificar un total de 106 especies de fitoplancteres, destacando los dinoflagelados Dinophysis acuta, D. acuminata y Alexandrium catenella, que han sido asociados a la producción de los Venenos Diarreico y Paralizante de Mariscos, y las diatomeas de los géneros Chaetoceros, Rhizosolenia, Pseudo-nitszchia y Leptocylindrus, que impactan la salmonicultura de la zona.

El fitoplancton se caracterizó por el predominio de diatomeas de aguas de baja salinidad sobre los otros grupos, apreciándose períodos en que aparecen especies características de aguas oceánicas, por lo que se utilizaron las especies de diatomeas como bioindicadores de los tipos de agua presentes en el fiordo. Esta evidencia permite establecer que el fitoplancton dentro del fiordo no sigue el patrón de sucesiones poblacionales, sino más bien una alternancia entre invasiones de especies de aguas continentales y marinas, al ambiente estuarino de la cabeza del fiordo.

La temperatura superficial del agua presentó fluctuaciones anuales normales para una región templada fría, con valores extremos de 5,2 y $16,2^{\circ} \mathrm{C}$, encontrándose los menores durante 1996 y los mayores en 1994 y 1998, presentando los últimos años una mayor persistencia de especies nocivas asociadas a toxinas.

Palabras clave: fitoplancton, fiordo, temperatura, Chile

\begin{abstract}
Temporal distribution of the phytoplankton in a fixed station inside Aysén fjord is described using 130 qualitative phytoplankton samples and water surface temperature measurements taken every 15 days from February 1993 till June 1998.

During the analysis a total of 106 species and varieties were identified: 74 corresponding to diatoms, 30 to dinoflagellates and 2 to silicoflagellates, being from marine neritical and oceanic, estuarine, continental and benthic habitats. Between the taxa identified we can point out three species related to toxin production: Alexandrium catenella (PSP), Dinophysis acuta and D. acuminata (DSP), and several other taxa which affect the salmon industry.

Phytoplankton was characterised by the predominance of low salinity diatoms over the other groups with periods in which species characteristic of oceanic waters appear. Therefore the diatoms present as bioindicators of the types of water in the fjord were used. This evidence demostrates that the phytoplankton within the fjord does not follow standard population successions, but reflects an alternation between invasions of species of continental and marine waters to the estuarine environment at the head of the fjord.

The water surface temperature presented normal annual fluctuations for a cold temperate region, with extreme values of $5,2^{\circ}$ and $16,2^{\circ} \mathrm{C}$, with the lowest during 1996 and the highest in 1994 and 1998 . The warmer years recording a high persistence of toxic species.

Key words: phytoplankton, fjord, temperature, Chile
\end{abstract}

\section{Introducción}

El seno Aysén constituye uno de los fiordos más importantes de la zona de senos y canales chilenos debido a su ubicación, forma, y utilización (Sievers \& Prado 1994). Este fiordo recibe las principales concentraciones humanas de la XI región, lo cual lo convierte en una zona de posibles perturbaciones ecológicas, incluyendo la aparición de floraciones algales nocivas (FAN), producidas por fitoplancteres dañinos a la salmonicultura y dinoflagelados tóxicos de los géneros Alexandrium y Dinophysis (Muñoz et al. 1992).

Existen escasas publicaciones referidas al fitoplancton de la zona sur de Chile, especialmente en la zona de canales que se inicia en Puerto Montt $\left(41^{\circ} 30^{\prime} \mathrm{S}\right)$ y se extiende hasta cabo de Hornos 
(5601'S) (Silva et al, 1995), estando la mayoría de los trabajos limitados a fenómenos puntuales o a zonas restringidas. Estas investigaciones fueron revisadas por Avaria et al. (1997), destacándose las llevadas a cabo por Muñoz et al. (1992), Romero (1994), Avaria (fide in Rivera 1985), Pickard (1971), Vera et al. (1996) y Avaria et al. (1999a). Además se cuenta con resultados de las expediciones LUND (Silva et al. 1995), MarChile I, HUDSON 70, Cimar-Fiordo I (Medina 1997) y Cimar-Fiordo IV (Avaria et al. 1999b). Sin embargo, no existen estudios previos que utilicen series de tiempo comparables en longitud e intensidad en la zona, exceptuando programas de monitoreo dirigidos hacia ficotoxinas ${ }^{1}$.

La mayor parte de las mareas rojas detectadas en Chile han sido provocadas por el ciliado Mesodinium rubrum y dinoflagelados inocuos. Sin embargo, desde 1970 se detectó la presencia de Veneno Diarreico de Mariscos (VDM) en Puerto Montt, provocado por Dinophysis sp. y, desde 1972 el Veneno Paralizante de Mariscos (VPM) en Magallanes, asociado a la especie Alexandrium catenella (Muñoz \& Avaria 1997).

En años recientes las especies asociadas con la producción de toxinas han incrementado su presencia y rango de distribución, fundamentalmente en el área de Puerto Montt ${ }^{2}$ y Aysén (Muñoz et al. 1992).

En el presente trabajo se dan a conocer las especies del fitoplancton que habitan el lugar, sus agrupaciones, la dinámica y variabilidad temporal de éstas y de la temperatura superficial del agua en las proximidades de la cabeza del seno Aysén, XI región, desde febrero de 1993 hasta junio de 1998. Dentro de este estudio se relacionan las apariciones de organismos asociados a VPM y VDM, y de aquellos dañinos a la salmonicultura con la temperatura superficial del agua y la presencia de otros fitoplancteres.

\footnotetext{
1 Tocornal M. 1998. Vigilancia epidemiológica a través del monitoreo sistematizado del litoral de Aysén, XI Región. Resúmenes Segundo Taller de Floraciones Algales Nocivas: ámbito de la salud humana, pesquerías y economía. Valparaíso, Chile.

2 Lembeye G, N Marcos, A Sfeir, F Jara, C Molinet, X Rojas \& A Clement. 1998. Seguimiento de la toxicidad en recursos pesqueros de importancia comercial en la $\mathrm{X}$ y XI Regiones. Resúmenes del XVIII Congreso de Ciencias del Mar, Iquique, Chile. p.170.
}

\section{Materiales y Métodos}

En la estación fija "Nueva Hammerfest", situada frente a punta Camello ( $\left.45^{\circ} 26^{\prime} \mathrm{S} 73^{\circ} 00^{\prime} \mathrm{W}\right)$, cerca de la cabeza del seno Aysén, XI Región, Chile (Fig. 1), se obtuvieron muestras quincenales de fitoplancton en superficie, mediante arrastres horizontales de 15 minutos, con una red de apertura de malla de $62 \mu \mathrm{m}$, desde el 9 de febrero de 1993 hasta el 14 de junio de 1998, siguiendo las recomendaciones de Ferrario et al. (1995). Simultáneamente se hicieron mediciones de temperatura superficial de agua utilizando termómetro de contacto.

Para la conservación de las muestras se utilizó formalina al 5\%, neutralizada con ácido bórico, para su posterior análisis en el laboratorio, efectuado con un microscopio fotónico Leitz Dialux 20, equipado con contraste de fases y un microscopio Leitz DM RBE, con equipo microfotográfico y rotulador automático Wild MPS 48/52.

En las determinaciones y actualizaciones taxonómicas se siguió principalmente a Cupp (1943), Avaria (1965, 1970), Rivera (1968, 1985), Guzmán \& Campodonico (1972), Rivera et al. (1973, 1982), Muñoz (1985), Taylor et al. (1995), Avaria et al. (1997), Balech (1988) y Tomas (1997).

Para estimar la abundancia relativa de las diferentes especies se utilizó la metodología propuesta por Avaria (1965), la que fue modificada por las características especiales del fitoplancton del seno Aysén, resultando la siguiente escala de clasificación:

- 0 Ausente, no se detecta la presencia de la especie.

- 1 Raro, se encuentra un ejemplar o cadena.

- 2 Escaso, menos de 10 ejemplares.

- 3 Abundante, entre 11 y 50 ejemplares.

- 4 Muy abundante, entre 51 y 80.

- 5 Floración, superior a 80, presentándose la especie en forma masiva.

Para este estudio se utilizaron mayoritariamente métodos gráficos por sobre los matemáticos, ya que el fitoplancton en la estación fija presenta dominancia de especies estuarinas, con irrupciones irregulares de aguas marinas y continentales, las que llevan dentro del fiordo especies diferentes en cada ocasión, impidiendo correlacionar sus diferentes apariciones, dependiendo de la etapa de la sucesión poblacional en que se encuentre el fitoplancton de las aguas provenientes del norte de la Convergencia Antártica (ASAA) y del grado de modificación que esta sufre por el aporte de agua dulce (Silva et al. 1999). 


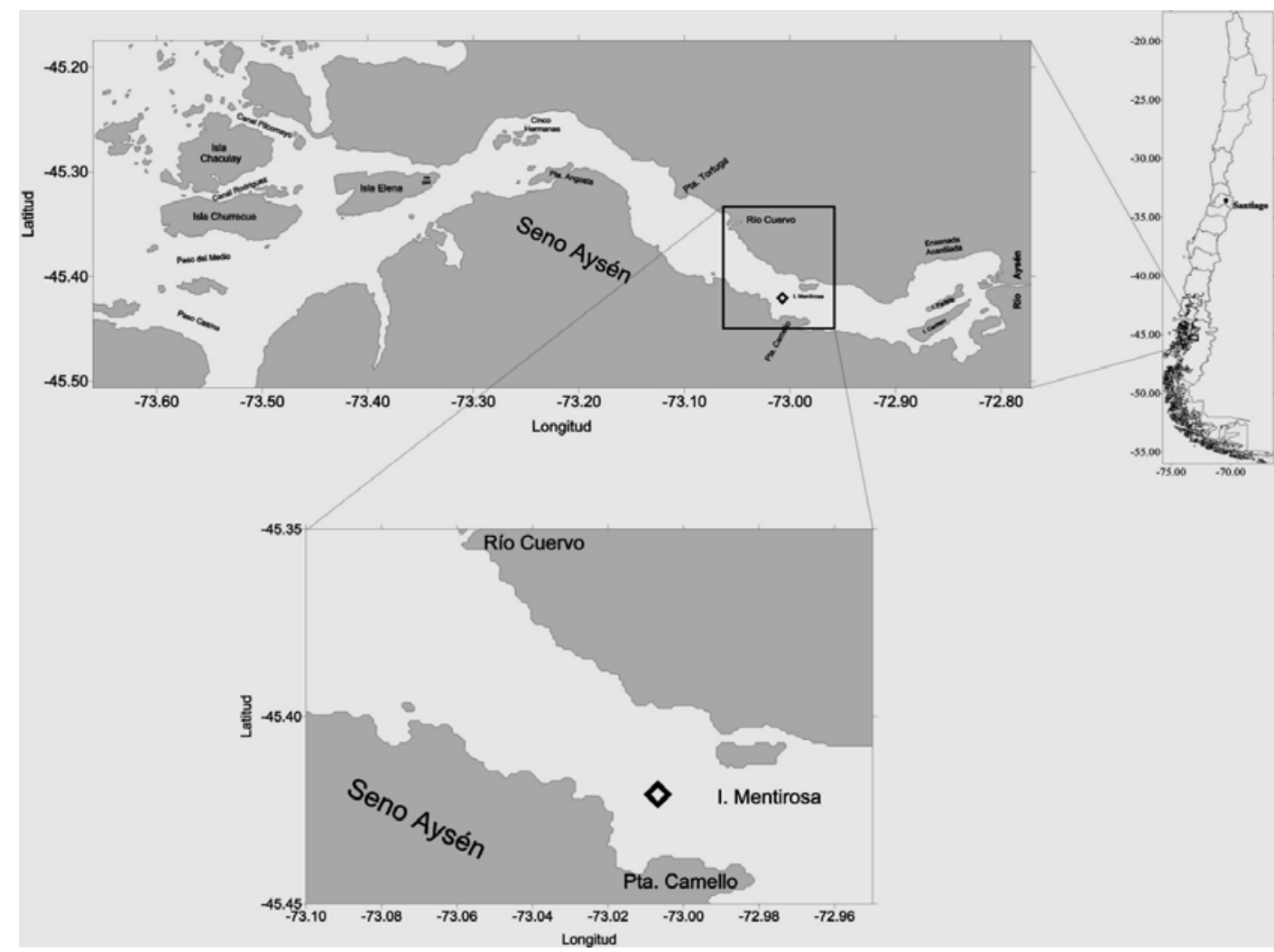

Figura 1

Ubicación geográfica de la estación fija en el seno Aysén, XI Región, Chile.

Geographical position of the fixed station in Aysen Fjord, XI Región, Chile.

Los datos de temperatura superficial se procesaron como promedios mensuales, anuales y totales, utilizándose los promedios matemáticos correspondientes.

Una aproximación cuantitativa se logró estimando la abundancia por gota alícuota, para lo cual se multiplicó la abundancia relativa con los valores medios señalados en la Tabla 1. En los gráficos los valores se expresan como número de células contadas en una gota de agua.

Utilizando la caracterización de los diferentes grupos de diatomeas por hábitat, como se muestra en la Tabla 2, y la abundancia estimada por gota alícuota, se obtuvo el porcentaje estimado que representa cada grupo de especies a lo largo del tiempo.

Las diatomeas identificadas fueron separadas por hábitat, con apoyo de bibliografía especializada, entre las que se encuentran los trabajos de Rivera (1968, 1974, 1975 y 1985), Rivera et al. (1982), Montecino (1985), Parra et al. (1984) y Uribe (1985).

Una vez separadas las especies por su hábitat se estimó la abundancia por grupo de diatomeas, sumando la abundancia estimada por gota alícuota de cada especie, para luego graficar los porcentajes que representa cada grupo.

Las especies nocivas asociadas a la producción de toxinas (VPM y VDM) fueron analizadas separadamente, para determinar su estacionalidad y preferencia de rango de temperatura, utilizándose gráficos de dispersión.

\section{Tabla 1}

Escala de abundancia relativa

Scale of relative abundance.

\begin{tabular}{|c|c|c|}
\hline $\begin{array}{c}\text { Escala } \\
\text { numérica }\end{array}$ & Especímenes & Denominación \\
\hline 1 & 1 & Raro \\
2 & 2 a 10 & Escaso \\
2.5 & 11 a 30 & Poco abundante \\
3 & 31 a 50 & Medianamente abundante \\
3.5 & 50 a 80 & Abundante \\
4 & $80+$ & Muy abundante \\
5 & Floración & Forma masiva \\
\hline
\end{tabular}


Tabla 2

\section{Diatomeas separadas por hábitat}

Diatoms separated by habitat.

\begin{tabular}{ll|}
\hline & Marino \\
\hline Asterionellopsis glacialis & Coscinodiscus janischii \\
Bacillaria paxillifera & Coscinodiscus sp. \\
Bacteriastrum sp. & Cylindrotheca closterium \\
Cerataulina pelagica & Detonula pumila \\
Chaetoceros affinis & Ditylum brightwellii \\
Chaetoceros compresus & Eucampia cornuta \\
Chaetoceros constrictus & Gramatophora marina \\
Chaetoceros convolutus & Guinardia delicatula \\
Chaetoceros curvisetus & Lauderia annulata \\
Chaetoceros debilis & Leptocilindrus danicus \\
Chaetoceros decipiens & Melosira moniliformis \\
Chaetoceros diadema & Navicula spp. \\
Chaetoceros didymus & Proboscia alata f. gracillima \\
Chaetoceros gracilis & Pseudo-nitzschia australis \\
Chaetoceros laciniosus & Pseudo-nitzschia cf. seriata \\
Chaetoceros lorenzianus & Pseudo-nitzschia delicatissima \\
Chaetoceros radicans & Rhizosolenia imbricata \\
Chaetoceros similis & Skeletonema costatum \\
Chaetoceros vistulae & Stephanopixis turris \\
Climacodium sp. & Thalassionema frauenfeldii \\
Corethron criophilum & Thalassiossira cf. decipiens \\
Coscinodiscus cf. centralis & Thalassiossira cf. delicatula \\
Coscinodiscus cf. perforatus & Thalassiossira cf. mendiolana \\
Coscinodiscus cf. radiatus & Thalassiossira cf. minuscula
\end{tabular}

\begin{tabular}{|lc|}
\hline & Estuarino \\
\hline Licmophora sp. & Synedra ulna \\
Rhizosolenia setigera & Thalassionema nitzschioides
\end{tabular}

Skeletonema costatum var.

Subsalsum

\begin{tabular}{ll|}
\hline & Limnético \\
\hline Asterionella formosa & Melosira italica \\
Ceratoneis arcus & Melosira pseudogranulata \\
Cymatopleura sp. & Melosira varians \\
Cymbella sp. & Navicula dicefala \\
Diploneis sp. & Pinnularia sp. \\
Fragilaria cf. construens & Plagiogramma sp. \\
Gomphonema sp. & Pleurosigma sp. \\
Melosira granulata & Rhizosolenia eriensis \\
Melosira hustedti &
\end{tabular}

\begin{tabular}{l|}
\hline \multicolumn{2}{|c|}{ Ticopelágico } \\
\hline Actinoptychus senarius \\
Gyrosigma sp.
\end{tabular}

\section{Resultados y discusión}

\section{Temperatura}

Durante el período de estudio, la temperatura superficial del agua presentó fluctuaciones anuales normales para una región templada fría, registrándose dos estaciones marcadas y un período de transición muy corto (Fig. 2).

La temperatura presentó grandes variaciones mensuales, siendo éstas mayores a comienzos de invierno e inicio de verano de cada año, cambiando drásticamente, especialmente cuando se presentaron lluvias o intrusiones de aguas marinas.

El promedio obtenido para todo el período fue de $10,8^{\circ} \mathrm{C}$, con valores extremos de 5,2 y $16,2^{\circ} \mathrm{C}$, presentándose los menores en 1996 y los mayores durante 1994 y 1998, lo que coincide con la aparición de eventos El Niño en el norte del país, que generaron cambios en el clima de la región al desplazarse el Anticiclón del Pacífico hacia el sur, favoreciendo la irradiación solar y el aumento de la temperatura ${ }^{3}$.

La temperatura promedio del año 1994 fue de $13,1^{\circ} \mathrm{C}$; luego ésta descendió, resultando 1995 con $10,4^{\circ} \mathrm{C}$ y 1996 con $8,9^{\circ} \mathrm{C}$, marcando a este último como el año más frío del período estudiado. El año 1997 muestra un alza en el promedio térmico con un valor de $10,2^{\circ} \mathrm{C}$, siendo comparable a 1995.

\section{Fitoplancton}

El fitoplancton presente en la cabeza del fiordo Aysén se caracterizó por una fuerte predominancia de las diatomeas sobre los demás grupos que lo conforman, apreciándose cambios en la composición específica, según el origen de la masa de agua predominante.

Durante el análisis de las muestras se identificaron 106 especies y variedades, correspondiendo 74 a diatomeas, 30 a dinoflagelados y 2 a silicoflagelados (Tabla 3). Dentro de éstas las hay de hábitat marino, nerítico, oceánico, estuarino, continental y especies ticoplanctónicas, destacando los taxa de aguas estuarinas durante el período estudio, por su número de apariciones, y las de hábitat marino, por el número de especies que componen este grupo.

\footnotetext{
${ }^{3}$ Arntz W. 1999. El fenómeno "El Niño" y sus implicaciones sobre el ambiente marino. Resúmenes del XIX Congreso de Ciencias del Mar, Chile, p.51.
} 


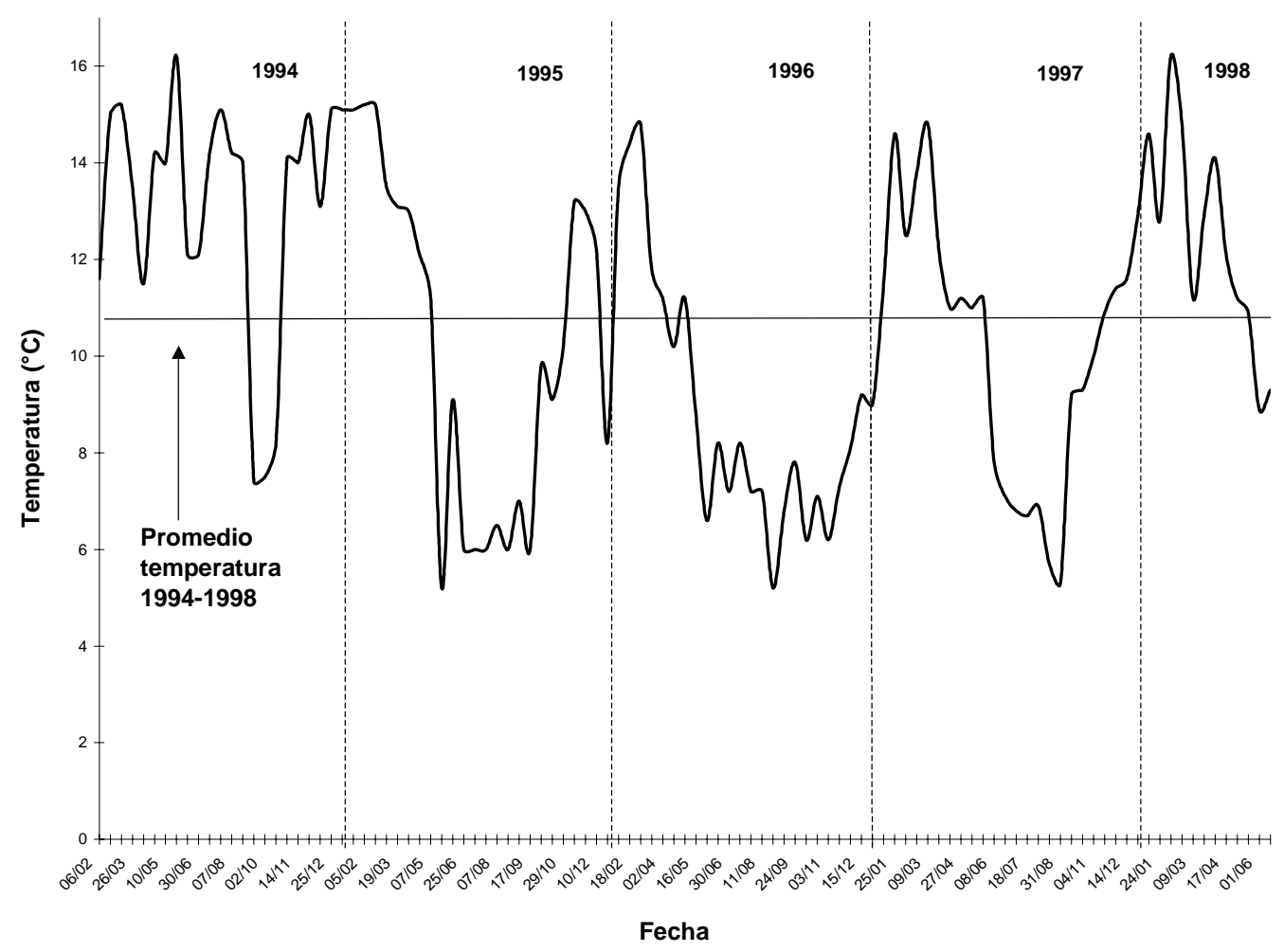

Figura 2

Perfil de temperatura superficial entre 1994 y 1998.

Water surface temperature between 1994 and 1998.

Tabla 3

Especies identificadas durante el muestreo.

Species identified in the samples.

Diatomeas

Actinoptychus senarius Ehrenberg 1838

Asterionella formosa Hassall 1850

Asterionellopsis glacialis (Castracane) Round 1990

Bacillaria paxillifera (Müller) Hendey 1964

Bacteriastrum sp.

Cerataulina pelagica (Cleve) Hendey 1937

Ceratoneis arcus (Ehrenberg) Kuetzing 1844

Chaetoceros affinis Lauder 1864

Chaetoceros compresus Lauder 1864

Chaetoceros constrictus Gran 1897

Chaetoceros convolutus Castracane 1886

Chaetoceros curvisetus Cleve 1889

Chaetoceros debilis Cleve 1894

Chaetoceros decipiens Cleve 1873

Chaetoceros diadema (Ehrenberg) Gran 1897

Chaetoceros didymus Ehrenberg 1845

Chaetoceros gracilis Schütt 1895

Chaetoceros laciniosus Schütt 1895
Chaetoceros lorenzianus Grunow 1863

Chaetoceros radicans Schütt 1895

Chaetoceros similis Cleve 1896

Chaetoceros sp.

Chaetoceros vistulae Apstein 1909

Climacodium sp.

Corethron criophilum Castracane 1886

Coscinodiscus cf. centralis Ehrenberg 1838

Coscinodiscus cf. perforatus Ehrenberg 1844

Coscinodiscus cf. radiatus Ehrenberg 1841

Coscinodiscus janischii Schmidt 1878

Coscinodiscus sp.

Cylindrotheca closterium (Ehrenberg) Reiman \& Lewin 1964

Cymatopleura sp.

Cymbella sp.

Detonula pumila (Castracane) Schütt 1896

Diploneis sp.

Ditylum brightwellii (West) Grunow (en Van Heurck 1880-1885)

Eucampia cornuta (Cleve) Grunow 1881 
Tabla 3 (continuación)

Fragilaria cf. construens (Ehrenberg) Grunow 1862

Gomphonema sp.

Grammatophora marina (Lingbye) Kützing 1844

Guinardia delicatula (Cleve) Hasle comb. nov.

Gyrosigma sp.

Lauderia annulata Cleve 1873

Leptocilindrus danicus Cleve 1889

Licmophora sp.

Melosira granulata (Ehrenberg) Ralfs (en Pritchard 1861)

Melosira hustedti Krasske 1939

Melosira italica (Ehrenberg) Kuetzing 1844

Melosira moniliformis (Müller) Agardh 1824

Melosira pseudogranulata Cleve-Euler 1948

Melosira varians Agardh 1817

Navicula dicefala Ehrenberg 1837

Navicula spp.

Paralia sulcata (Ehrenberg) Cleve 1873

Pinnularia sp.

Plagiogramma sp.

Pleurosigma sp.

Proboscia alata f. gracillima (Brightwell) Sundström 1986

Pseudo-nitzschia cf. seriata (Cleve) Peragallo 1908

Pseudo-nitzschia cf. australis Frenguelli 1939

Pseudo-nitzschia delicatissima (Cleve) Heiden (en Heiden \& Kolbe 1928)

Rhizosolenia eriensis Smith 1872

Rhizosolenia imbricata Brightwell 1858

Rhizosolenia setigera Brightwell 1858

Skeletonema costatum (Greville) Cleve 1878

Skeletonema costatum var subsalsum

Stephanopixis turris (Greville \& Arnott) Ralfs (en Pritchard 1861)

Synedra ulna (Nitzsch) Ehrenberg 1838

Thalassionema frauenfeldii (Grunow) Hallegraeff 1986

Thalassionema nitzschioides (Grunow) Mereschkowsky 1902

Thalassiossira cf. decipiens (Grunow) Jorgensen (en Hasle 1979)

Thalassiossira cf. delicatula Ostenfeld 1980

Thalassiossira cf. mendiolana Hasle \& Heimdal 1970

Thalassiossira cf. minuscula Krasske 1941

\section{Dinoflagelados}

Alexandrium catenella (Whedon \& Kofoid) Balech 1985

Ceratium fusus var. seta (Ehrenberg) Dujardin 1841

Ceratium macroceros var. macroceros (Ehrenberg)

VanHöffen 1897

Ceratium pentagonum var. robustum (Cleve) Jorgensen 1920

Dinophysis acuminata Claparède \& Lachmann 1859

Dinophysis acuta Ehrenberg 1839

Dinophysis fortii Pavillard 1923

Dinophysis hastata Stein 1883

Diplopsalis lenticula Bergh 1882

Diplopsalis minor (Paulsen) Silva 1907

Gonyaulax spinifera (Claparède \& Lachman) Diesing 1866
Heterocapsa triquetra (Ehrenberg) Stein 1883

Phalacroma rotundatum (Claparède \& Lachmann) Kofoid \&

Michener 1911

Protoperidinium claudicans (Paulsen) Balech 1974

Protoperidinium conicum (Gran) Balech 1974

Protoperidinium crassipes (Kofoid) Balech 1974

Protoperidinium depressum (Bailey) Balech 1974

Protoperidinium divergens (Ehrenberg) Balech 1974

Protoperidinium leonis (Pavillard) Balech 1974

Protoperidinium obtusum (Karsten) Parke \& Dodge 1976

Protoperidinium oceanicum (VanHöffen) Balech 1974

Protoperidinium pedunculatum (Schütt) Balech 1974

Protoperidinium pellucidum Bergh 1881

Protoperidinium pentagonum (Gran) Balech 1974

Protoperidinium punctulatum (Paulsen) Balech 1974

Protoperidinium steinii (Jorgensen) Balech 1974

Protoperidinium sympholis

Pyrocistis sp.

Pyrophacus steinii (Schiller) Wall \& Dale 1971

Scrippsiella trochoidea (Stein) Loeblich III 1976

\section{Silicoflagelados}

Dictyoch fibula Ehrenberg 1840

Dictyocha speculum Ehrenberg 1839

Dentro de los taxa identificados destacan los r-estrategas por la gran abundancia estimada que alcanzaron, y los K-estrategas, que fueron mejor representados durante las intrusiones marinas; esta diferencia se debe a la poca estabilidad que se presenta en la capa fótica del fiordo, ya que existe una alta tasa de renovación de las aguas superficiales, especialmente en invierno, cuando existe una mayor descarga de aguas continentales (Silva et al. 1999).

Durante esta investigación se encontró un mayor número de especies y variedades que en los estudios realizados anteriormente en la zona. Se citan por primera vez para el área: Actinoptychus senarius, Ceratoneis arcus, Lauderia annulata, Melosira husdtedtii, M. italica, Navicula dicefala, Proboscia alata f. gracillima, Dinophysis hastata, Gonyaulax spinifera, Protoperidinium crassipes, $P$. pentagonum, $P$. sympholis, Pyrophacus steinii y Dictyocha fibula, destacando el hecho de que estas especies son principalmente de tres hábitats: marino de aguas cálidas, bentónico y de aguas continentales.

Cabe hacer notar la aparición en el fiordo de especies relacionadas a aguas marinas cálidas, utilizadas como bioindicadores de la presencia de fenómenos El Niño en el norte del país (Avaria 1993), lo que 
evidencia grandes movimientos de agua en la zona de seno Aysén (Silva et al. 1999)

La diatomea eurihalina y euriterma Skeletonema costatum, fue la especie más abundante registrada durante el período de muestreo, presentándose en dos morfotipos bien diferenciados, los que anteriormente se habían relacionado a la salinidad y a la presión osmótica del medio (Romero 1994). Esto permitió evidenciar las intrusiones de aguas marinas y la influencia de las aguas continentales dentro del fiordo, mediante la observación de la proporción entre ambos morfotipos presentes en las muestras.

En general entre las diatomeas destaca aquellos taxa correspondientes al hábitat marino, comparado con el reducido número de especies estuarinas, las que, sin embargo, dominan en abundancia.

En los primeros meses de 1993 (Fig. 3) las diatomeas estuarinas aparecieron como dominantes, con porcentajes cercanos al 100\% hasta abril, cuando se presentaron especies marinas por un breve período, durante el cual alcanzan el 50\% de la composición específica. Esta invasión de especies marinas es rápidamente disgregada por movimientos de agua, detectados desde el 20 de abril hasta el 1 de junio, evidenciado por la gran cantidad de taxa ticopelágicos y continentales, los cuales se hicieron presentes junto a los fitoplancteres estuarinos.

Durante y después de la aparición de especies ticopelágicas, se registró un corto período de mezcla, caracterizado por $35 \%$ de diatomeas marinas, un pequeño aporte de taxa continentales y más del 60\% de origen estuarino, situación que persistió hasta el 15 de junio, cuando hubo otra irrupción de especies marinas. Estas últimas alcanzaron cerca del $70 \%$ de la abundancia estimada hasta el 24 de agosto, fecha en que se produjo una irrupción de aguas continentales, dando como resultado un período de presencia de especies estuarinas que dura hasta el 19 de septiembre.

En octubre y noviembre del mismo año, se presentó otra irrupción de aguas marinas, con una pequeña componente continental. El mes de diciembre se caracterizó por una brusca disminución de las especies marinas y un aumento importante de las continentales y estuarinas.

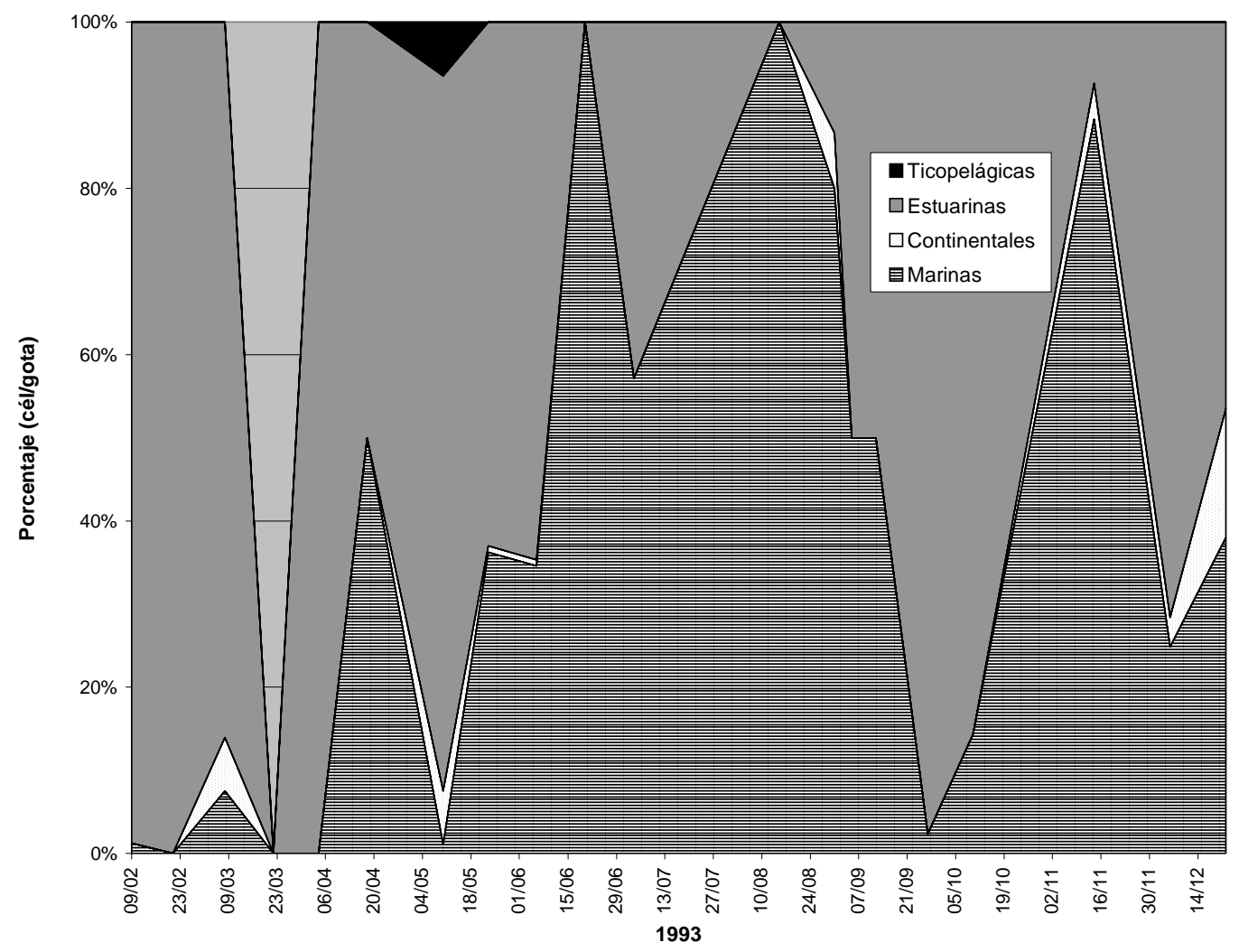

Figura 3

Porcentaje de cada grupo de diatomeas separadas por hábitat durante 1993.

Percentage of each group of diatoms separated by habitat for 1993. 
En enero de 1994 (Fig. 4) se presentó una dominancia de diatomeas de aguas estuarinas, con influencia moderada de especies marinas y una pequeña componente proveniente de los ríos. Desde inicios de febrero los taxa marinos cobraron una mayor importancia, llegando a representar el 50\% el día 11, descendiendo bruscamente el 25 de este mes por una invasión de especies continentales.

El mes de marzo se caracterizó por especies marinas que llegaron al $80 \%$ de la abundancia estimada y una considerable reducción de los taxa continentales y estuarinos. Sin embargo, al inicio de abril los taxa dominantes fueron los de aguas estuarinas, siendo reemplazados rápidamente por los de origen marino.

Desde los últimos días de abril hasta finales de julio, el fitoplancton se caracterizó por presentar sucesivas intrusiones de diferentes grupos de especies. Este período comenzó con una predominancia de diatomeas marinas, las que fueron rápidamente reemplazadas por una mezcla de todos los grupos, con predominio de diatomeas continentales (40\%). Los demás grupos se registraron con porcentajes cercanos al $20 \%$.

A mediados de julio las diatomeas marinas volvieron a tomar importancia, llegando a representar el 75\% de las especies presentes. Esta presencia de taxa marinos se vio interrumpida por un mes de dominancia plena de representantes de aguas estuarinas, el que se prolongó hasta finales de agosto.

Desde septiembre hasta el fin del año 1994, la composición de diatomeas experimentó variaciones menores a las observadas durante los meses anteriores. Las especies continentales aumentaron notoriamente hacia diciembre, desde mediados de agosto, donde representaron un porcentaje muy bajo, hasta alcanzar valores cercanos al $50 \%$ a principios de diciembre. Durante este período las especies marinas variaron su representación desde un $50 \%$ a principios de agosto hasta $10 \%$ a mediados de diciembre, mientras que las estuarinas mantuvieron valores mayores al $40 \%$.

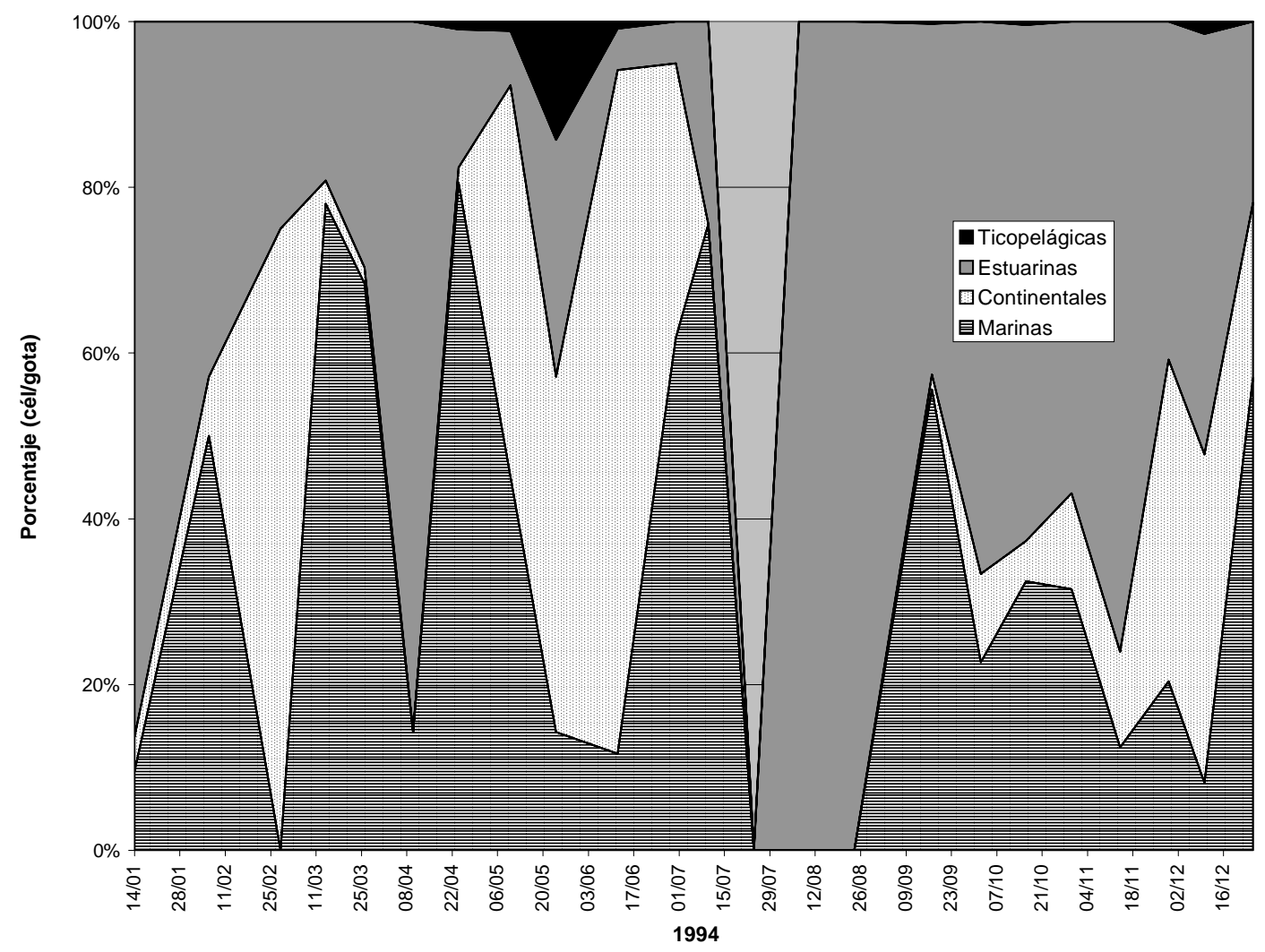

Figura 4

Porcentaje de cada grupo de diatomeas separadas por hábitat durante 1994.

Percentage of each group of diatoms separated by habitat for 1994. 
Durante el año 1995 (Fig. 5) las especies marinas se presentaron con valores superiores al $20 \%$, excepto en mayo, cuando ocurrió una gran aparición de especies continentales, las que llegaron a representar el $90 \%$ de la abundancia estimada. Además de esta irrupción, se presentaron tres invasiones importantes de aguas marinas en el fiordo. La primera ocurre desde finales de febrero hasta mediados de marzo, donde estas especies llegaron a ocupar hasta el 90\%; esta irrupción marina continuó con menor intensidad hasta principios de mayo, donde fue interrumpida por la gran presencia de aguas continentales detectada en mayo.

El segundo máximo que presentaron las diatomeas marinas ocurrió entre junio y julio, finalizando la dominancia de las especies continentales. Esta irrupción es la de menor importancia de las tres irrupciones marinas, aunque llegó a valores de hasta el 80\%.

A mediados de julio aparecieron especies ticopelágicas y continentales; luego de esta interrupción se produce la tercera invasión marina, la que sucedió durante septiembre, ocupando hasta el 85\%. Esta dominancia de especies marinas se interrumpió brevemente el 16 de octubre, para luego alcanzar un valor cercano al 50\%, lo cual fue de corta duración ya que las diatomeas continentales volvieron a cobrar importancia, aumentando su representación hasta llegar al $20 \%$ y las estuarinas al $60 \%$, disminuyendo rápidamente las especies marinas hacia diciembre.

En el transcurso de la primera parte de 1996 (Fig. 6) se continuó la tendencia marina de 1995, cubriendo cerca del 70\% de la abundancia estimada; sin embargo, esta influencia disminuye rápidamente hacia marzo, aumentando las especies estuarinas y continentales.

En 1996 se observó tres grandes intrusiones de especies marinas de gran intensidad, aunque de corta duración; tal fue el caso de mayo, luego de la presencia de diatomeas continentales muy intensa. Durante este episodio las especies marinas alcanzaron sobre el $90 \%$ de la abundancia estimada, siendo rápidamente reemplazadas por especies estuarinas, las que ocuparon el $100 \%$.

Luego de este rápido cambio, las especies marinas volvieron a aparecer desde julio hasta finales de agosto, presentando abundancias estimadas superiores al $90 \%$.

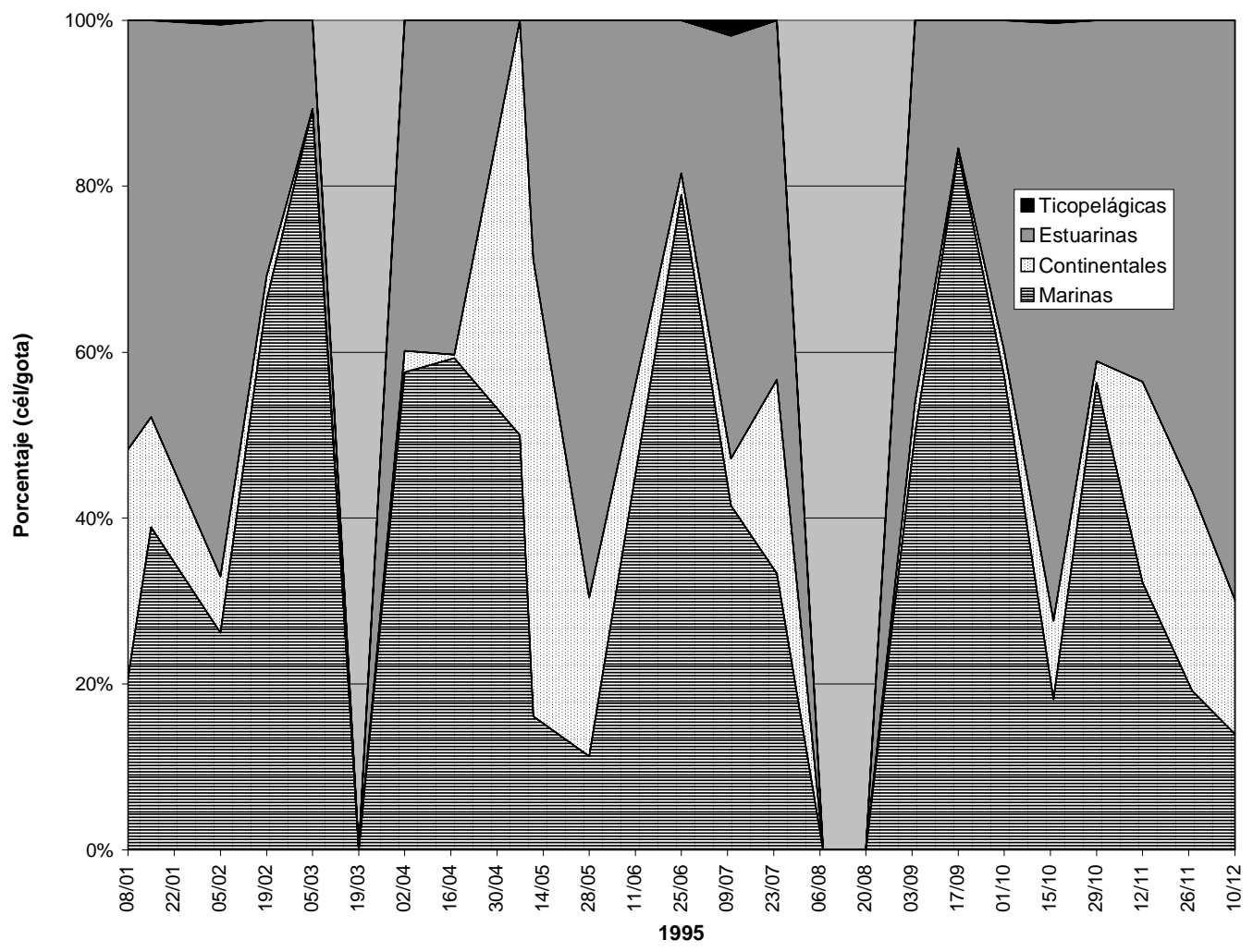

Figura 5

Porcentaje de cada grupo de diatomeas separadas por hábitat durante 1995.

Percentage of each group of diatoms separated by habitat for 1995. 


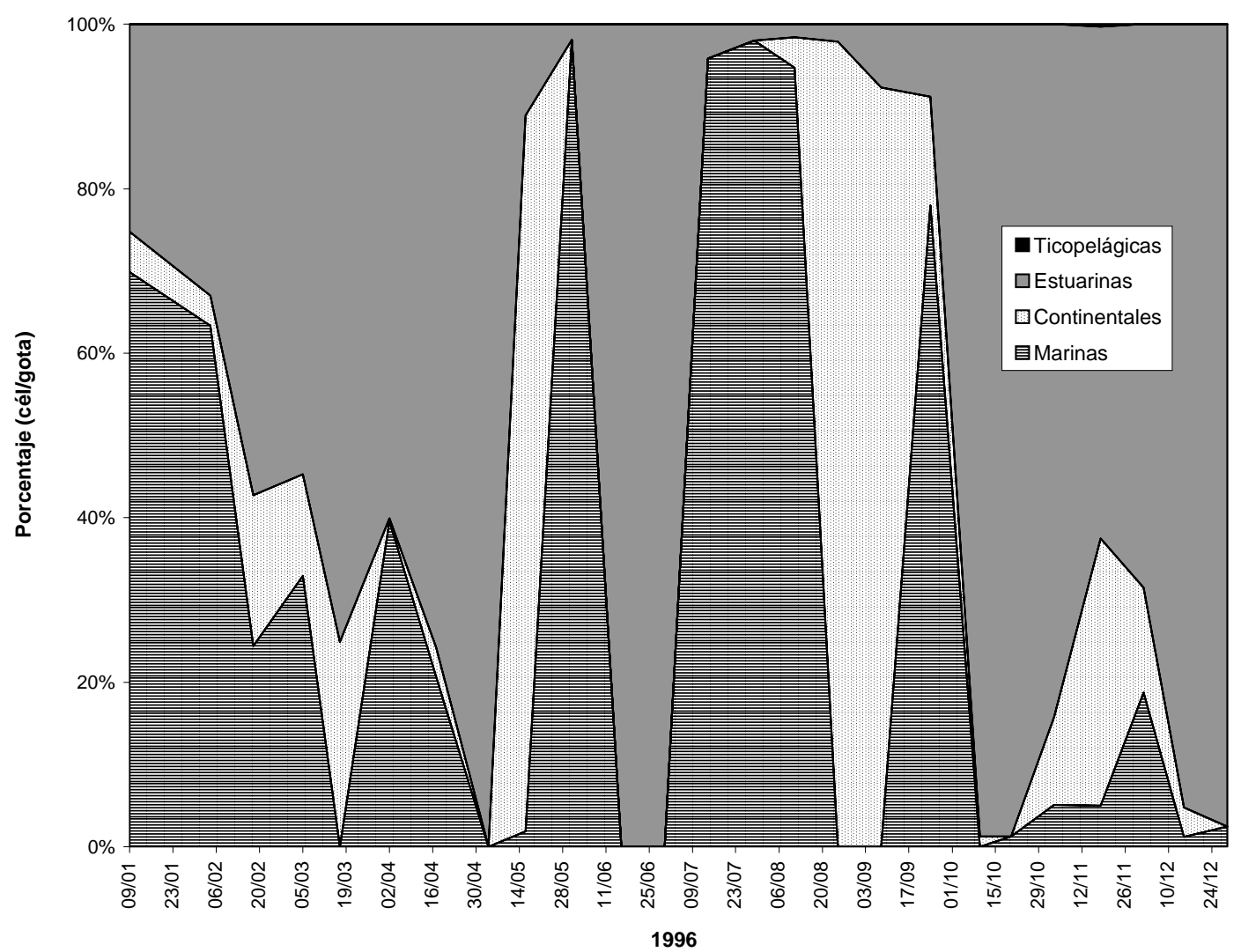

Figura 6

Porcentaje de cada grupo de diatomeas separadas por hábitat durante 1996.

Percentage of each group of diatoms separated by habitat for 1996.

Desde principios de agosto hasta mediados de septiembre las diatomeas marinas fueron reemplazadas por continentales; sin embargo, éstas decaen rápidamente, siendo superadas, una vez más, por los fitoplancteres de aguas más salinas desde mediados de septiembre. Estas últimas llegan a cubrir hasta el $80 \%$ por un corto período, el que se extiende hasta el 16 de octubre, fecha en que las especies estuarinas cubren la mayor parte de la abundancia estimada.

En los últimos meses del año se produjo una dominancia de las especies estuarinas sobre los otros grupos; sin embargo, durante este período existió una pequeña presencia de diatomeas marinas, las que alcanzan como máximo un valor inferior al $20 \%$ a finales de noviembre, junto a especies de agua dulce, las que alcanzan hasta un $30 \%$ a mediados de noviembre.

Durante enero de 1997 (Fig. 7), la influencia marina alcanzó cerca del $40 \%$, pero un aumento de las diatomeas continentales disminuyó la influencia marina a menos del $20 \%$. Sin embargo, en marzo y abril las especies marinas dominan, llegando a cubrir sobre el $90 \%$.

A pesar de la gran abundancia alcanzada, las especies de aguas de alta salinidad decayeron rápidamente a principios de mayo, siendo reemplazadas por diatomeas continentales y estuarinas, las que dominaron durante 15 días, siendo desplazadas nuevamente por un gran florecimiento de especies marinas, el que alcanza valores cercanos al 100\%, prolongándose hasta mediados de agosto.

Nuevamente, en septiembre se presentó una invasión de especies continentales, la que disminuyó su influencia paulatinamente hacia fines de este mes, cuando las especies marinas volvieron a florecer, alcanzando el $80 \%$ de la abundancia por un breve período, el cual se extendió hasta mediados de octubre. Durante los últimos dos meses del año dominaron las especies estuarinas, con valores cercanos al $80 \%$. 


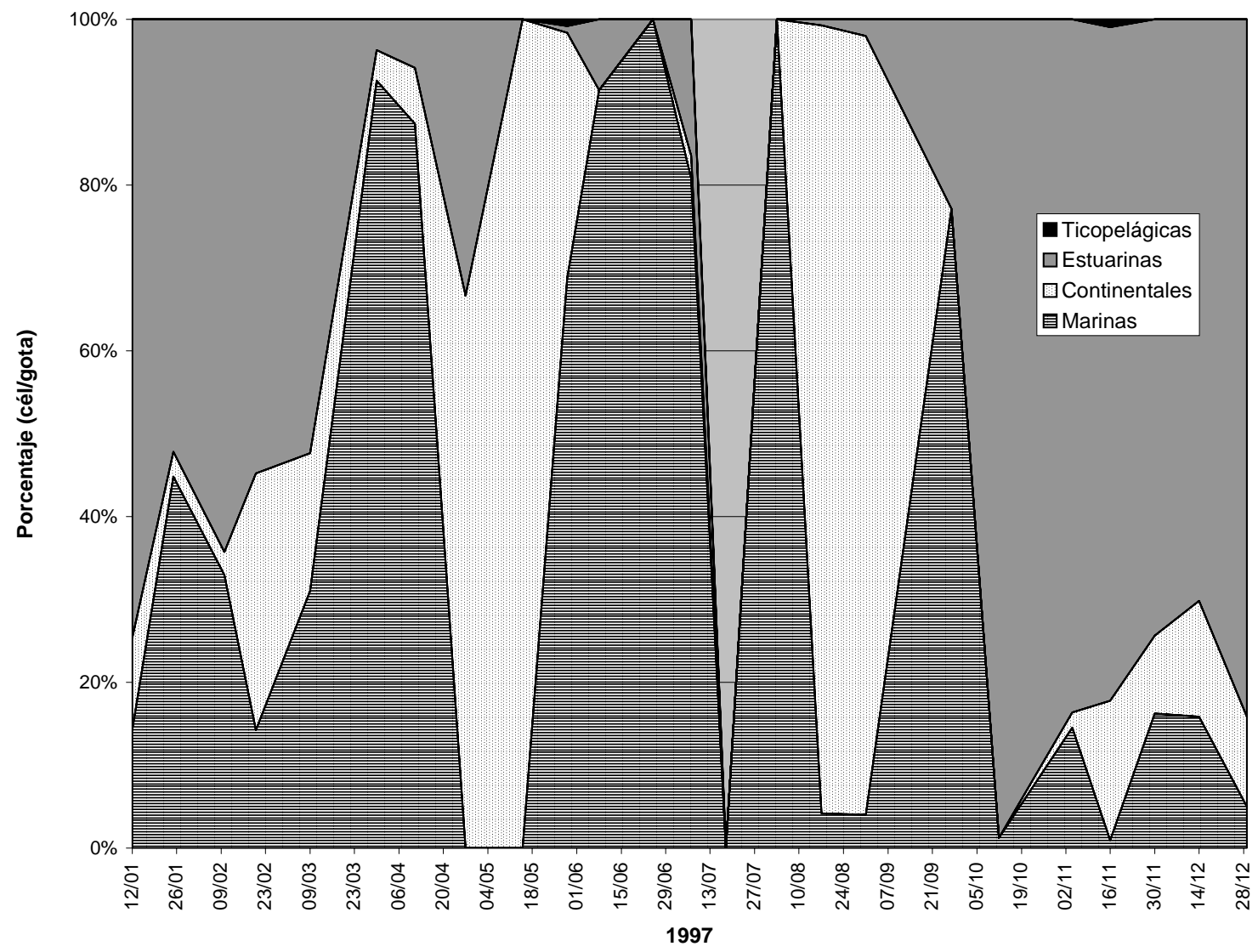

Figura 7

Porcentaje de cada grupo de diatomeas separadas por hábitat durante 1997. Percentage of each group of diatoms separated by habitat for 1997.

La figura 8 presenta las variaciones ocurridas en la abundancia durante los primeros seis meses de 1998, donde las especies marinas se presentaron en altos porcentajes entre febrero y marzo, y desde mediados de abril hasta junio, llegando a valores sobre el $90 \%$ de la abundancia estimada.

Durante este período las diatomeas estuarinas se presentaron en baja abundancia, llegando a cubrir hasta el $60 \%$ en dos períodos, enero y finales de marzo, presentándose en el primero con alta influencia continental, mientras que en el segundo se muestra con mezcla de especies ticopelágicas.

A finales de junio aparecieron especies ticopelágicas y continentales, las que señalaron el fin de la dominancia marina en la zona.

Debido a las características especiales de la circulación oceanográfica que posee el fiordo Aysén, en la que se presentan intrusiones de aguas marinas y continentales en superficie en la cabeza del seno, se ha podido establecer que el fitoplancton en este sector no sigue el patrón de sucesiones poblacionales, sino una dominancia de las especies estuarinas con sucesivas invasiones de diferentes grupos de plancteres marinos y continentales.

Las intrusiones marinas normalmente se presentaron sin especies precursoras, en forma abrupta y con gran abundancia estimada inicial, la que decrece paulatinamente. El término de estos procesos se ve marcado en numerosas ocasiones por la aparición de especies continentales y ticopelágicas, evidenciando estas últimas gran movimiento vertical en la columna del agua, especialmente durante la estación lluviosa, cuando además se presenta abundancia de especies continentales, lo que señala el aumento del aporte de agua dulce. 


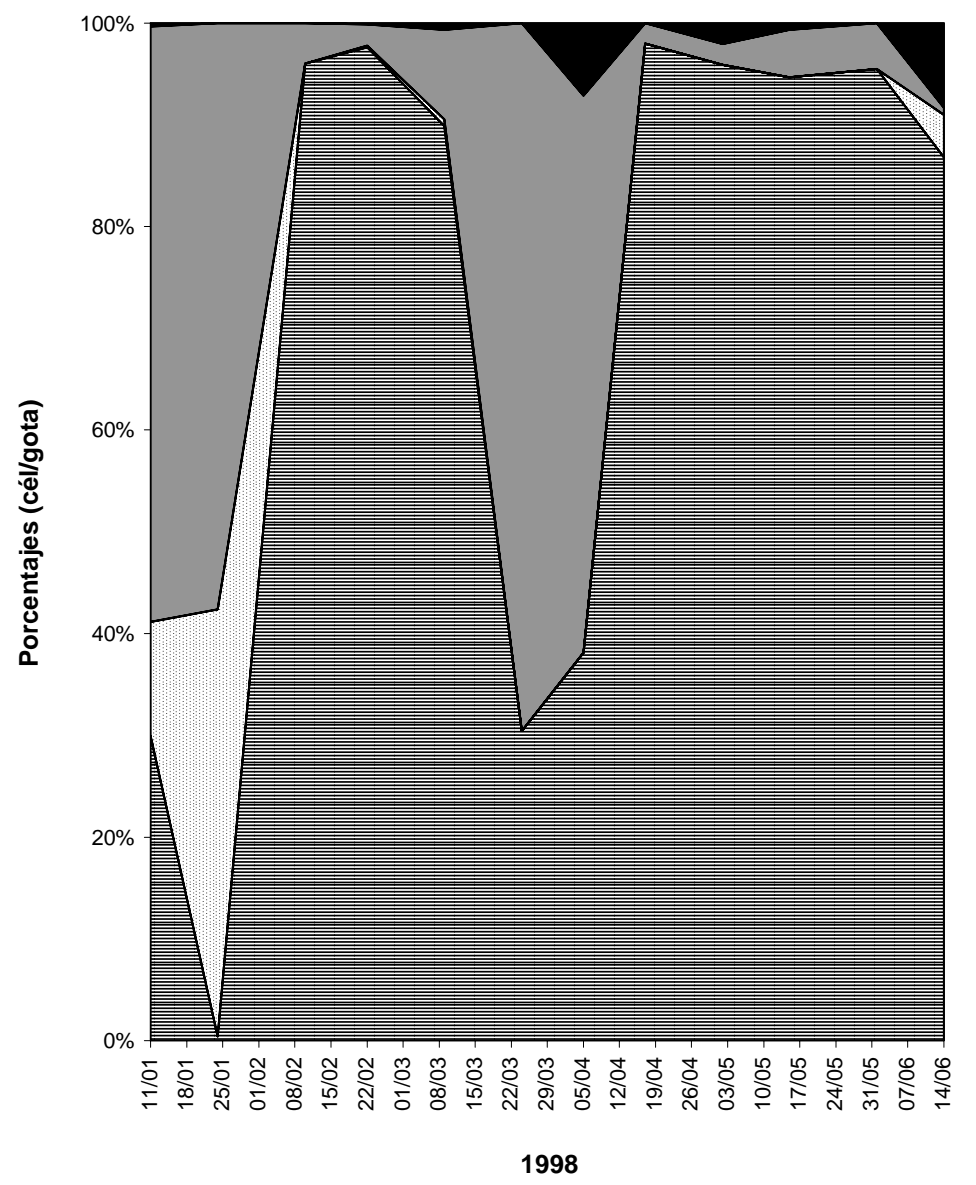

Ticopelágicas $\square$ Estuarinas $\square$ Continentales 目Marinas

\section{Figura 8}

Porcentaje de cada grupo de diatomeas separadas por hábitat durante 1998. Percentage of each group of diatoms separated by habitat for 1998.

Durante todo el período muestreado, las especies estuarinas fueron las que presentaron los porcentajes más altos de abundancia estimada. Los valores que presentó esta fracción de los taxa identificados, fueron siempre mayores al $40 \%$ y con grandes fluctuaciones (Fig. 9).

En 1993 las especies de hábitat estuarino representaron cerca del $60 \%$ de la abundancia, para luego decrecer en 1994 hasta el 40\%, valor que fue mantenido durante 1995. En 1996 se presentó un alza en estas especies, las que ocuparon aproximadamente el $50 \%$ de la abundancia estimada; esta tendencia fue mantenida en 1997, año en que superaron el 50\%.

El año 1998 fue considerado un caso especial, al contarse solamente con muestras del primer semestre, quedando el promedio interrumpido sin el período de invierno y primavera, donde los aportes de aguas de baja salinidad son mayores. Durante este período las especies marinas dominaron con un valor cercano al $80 \%$ de la abundancia estimada, quedando el porcentaje restante dividido entre los grupos de hábitats de menor salinidad, con especies estuarinas representando cerca del 15\% y continentales menos del 5\%. Las especies ticopelágicas tuvieron una pequeña representación durante todo el muestreo, significando menos del 1\% de la abundancia estimada.

Utilizando los valores de células por gota, divididos en las agrupaciones por hábitat en un gráfico acumulativo (Fig. 10), se puede observar una dominancia de las especies estuarinas por sobre los otros grupos durante 1993 y 1994. Desde 1995 hasta 1998 la dominancia se ve disputada por los grupos marino y estuarino, mientras que los otros mantienen valores menores. 


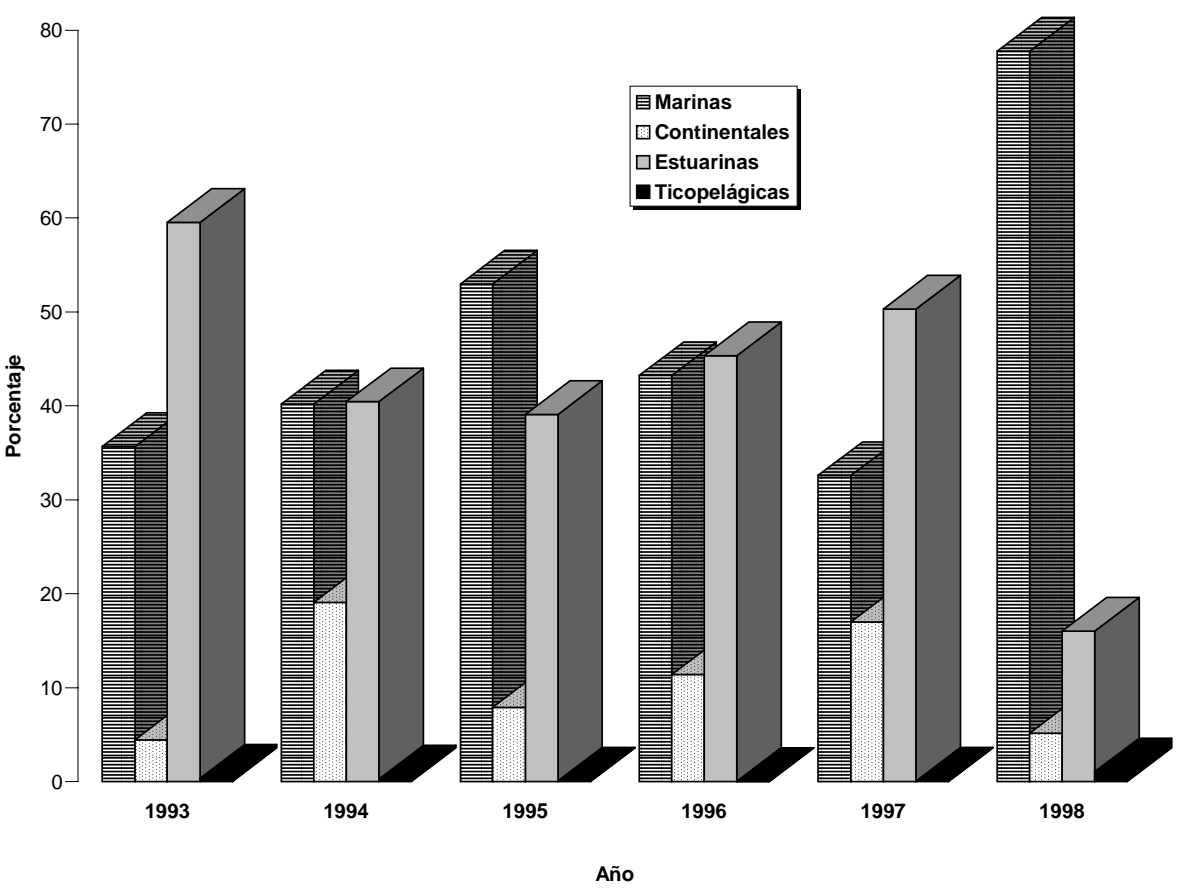

Figura 9

Porcentaje anual de las diatomeas separadas por hábitat.

Anual percentage of each group of diatoms separated by habitat.

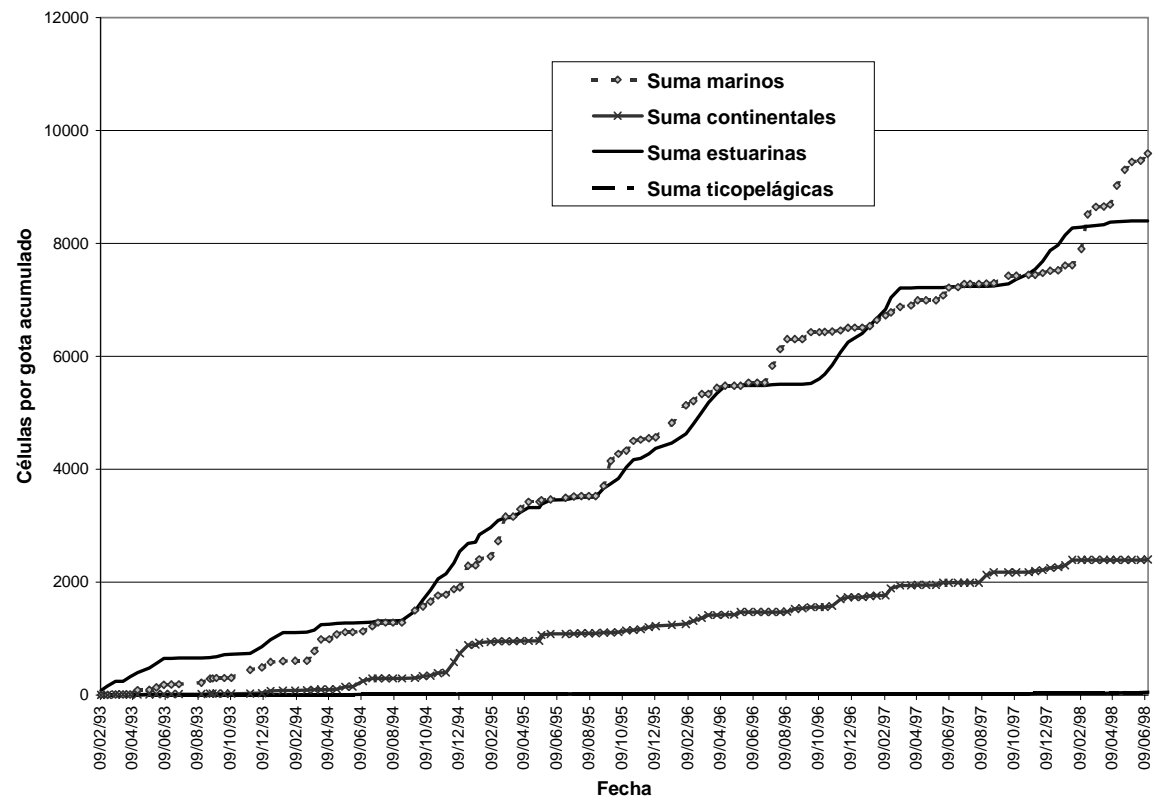

Figura 10

Abundancia estimada acumulada de las diatomas por hábitat.

Accumulated estimated abundance of the diatoms separated by habitat. 
El perfil de las especies de aguas estuarinas presentó un crecimiento continuo desde febrero de 1993 hasta abril de 1995, cuando ocurre un período de baja acumulación en la curva, el que duró hasta septiembre de ese año, fecha en que se reinicia la presencia de este grupo. Este comportamiento de la curva se mantiene hasta marzo de 1996, mes en que se vuelve a tener crecimiento nulo en la curva, situación que se mantiene hasta noviembre de ese año, cuando se presenta un incremento súbito que se prolonga hasta marzo de 1997, para luego volver a un estado de leve crecimiento que se detecta hasta octubre. Este fue seguido por un período de gran acumulación hasta febrero de 1998, para luego volver a un bajo crecimiento hasta junio de ese mismo año.

Al igual que el grupo de especies estuarinas, las de hábitat marino presentaron períodos de gran abundancia estimada, alternados con etapas de baja presencia, los que siguieron un patrón definido; alto crecimiento de la curva en los meses de verano (septiembre-marzo) seguido por baja presencia en los meses de invierno (abril-agosto). Sin embargo, este patrón no es tan regular como el observado para las especie estuarinas.

La curva de las especies de origen continental presentó un crecimiento constante durante todo el período muestreado, sin embargo, este grupo tuvo una notable alza en diciembre de 1994. El grupo de especies ticopelágicas no tuvo una gran representación en las muestras analizadas.

Al tomar en consideración el número de apariciones registrado por cada especie, se observó que el taxón que presentó el valor más alto fue Skeletonema costatum, en su morfotipo de agua dulce, en 82 ocasiones, seguido por Thalassionema nitzschioides en 64, Skeletonema costatum morfotipo de aguas marinas en 51, Ceratium macroceros var. macroceros en 51 y Melosira pseudogranulata en 46, todos de un total de 130 muestras (tabla 4).

\section{Tabla 4}

Número de muestras positivas por especie. Number of positive samples er specie.

\begin{tabular}{|l|c|}
\hline \multicolumn{1}{|c|}{ Especie } & Apariciones \\
\hline Skeletonema costatum var. subsalsum & 82 \\
Thalassionema nitzschioides & 64 \\
Thalassiossira cf. mendiolana & 52 \\
Skeletonema costatum & 51 \\
Ceratium macroceros var. macroceros & 51 \\
Navicula sp. & 49 \\
Melosira pseudogranulata & 46 \\
Ditylum brightwellii & 45 \\
Ceratium fusus var. seta & 43 \\
\hline
\end{tabular}

\begin{tabular}{|c|c|}
\hline Rhizosolenia setigera & 41 \\
\hline Licmophora sp. & 40 \\
\hline Dinophysis acuminata & 40 \\
\hline Sinedra ulna & 39 \\
\hline Thalassionema frauenfeldii & 36 \\
\hline Ceratium pentagonum var. robustum & 35 \\
\hline Asterionella formosa & 34 \\
\hline Dinophysis acuta & 32 \\
\hline Diplopsalis minor & 30 \\
\hline Protoperidinium obtusum & 27 \\
\hline Thalassiossira cf. decipiens & 26 \\
\hline Rhizosolenia eriensis & 25 \\
\hline Melosira varians & 23 \\
\hline Dictyocha speculum & 23 \\
\hline Melosira moniliformis & 22 \\
\hline Protoperidinium pellucidum & 22 \\
\hline Chaetoceros affinis & 20 \\
\hline Chaetoceros lorenzianus & 20 \\
\hline Phalacroma rotundatum & 19 \\
\hline Chaetoceros convolutus & 18 \\
\hline Corethron criophilum & 16 \\
\hline Cylindrotheca closterium & 16 \\
\hline Pseudo-nitzschia australis & 16 \\
\hline Protoperidinium oceanicum & 16 \\
\hline Melosira granulata & 15 \\
\hline Asterionellopsis glacialis & 14 \\
\hline Diploneis sp. & 13 \\
\hline Chaetoceros diadema & 12 \\
\hline Navicula dicefala & 12 \\
\hline Pseudo-nitzschia delicatissima & 12 \\
\hline Thalassiossira cf. delicatula & 12 \\
\hline Protoperidinium pedunculatum & 12 \\
\hline Leptocilindrus danicus & 11 \\
\hline Melosira italica & 11 \\
\hline Pinnularia sp. & 11 \\
\hline Diplopsalis lenticula & 11 \\
\hline Actinoptychus senarius & 10 \\
\hline Chaetoceros constrictus & 10 \\
\hline Chaetoceros radicans & 10 \\
\hline Gyrosigma sp. & 10 \\
\hline Ceratoneis arcus & 9 \\
\hline Coscinodiscus cf. perforatus & 9 \\
\hline Coscinodiscus janischii & 9 \\
\hline Stephanopixis turris & 9 \\
\hline Cerataulina pelagica & 8 \\
\hline Chaetoceros didymus & 8 \\
\hline Alexandrium catenella & 8 \\
\hline Chaetoceros curvisetus & 7 \\
\hline Chaetoceros debilis & 7 \\
\hline Chaetoceros laciniosus & 7 \\
\hline Cymbella sp. & 7 \\
\hline Protoperidinium steinii & 7 \\
\hline Proboscia alata f. gracillima & 6 \\
\hline Heterocapsa triquetra & 6 \\
\hline Protoperidinium leonis & 6 \\
\hline Chaetoceros similis & 5 \\
\hline Chaetoceros sp. & 5 \\
\hline
\end{tabular}


Tabla 4 (continuación)

\begin{tabular}{|c|c|}
\hline Chaetoceros vistulae & 5 \\
\hline Detonula pumila & 5 \\
\hline Grammatophora marina & 5 \\
\hline Melosira hustedti & 5 \\
\hline Dictyoch fibula & 5 \\
\hline Lauderia annulata & 4 \\
\hline Bacillaria paxillifera & 4 \\
\hline Pseudonitzschia cf. seriata & 4 \\
\hline Rhizosolenia imbricata & 4 \\
\hline Protoperidinium punctulatum & 4 \\
\hline Bacteriastrum sp. & 3 \\
\hline Chaetoceros decipiens & 3 \\
\hline Chaetoceros gracilis & 3 \\
\hline Coscinodiscus cf. centralis & 3 \\
\hline Coscinodiscus cf. radiatus & 3 \\
\hline Coscinodiscus sp. & 3 \\
\hline Protoperidinium divergens & 3 \\
\hline Protoperidinium pentagonum & 3 \\
\hline Pyrophacus steinii & 3 \\
\hline Chaetoceros compresus & 2 \\
\hline Cymatopleura sp. & 2 \\
\hline Paralia sulcata & 2 \\
\hline Guinardia delicatula & 2 \\
\hline Thalassiossira cf. minuscula & 2 \\
\hline Protoperidinium depressum & 2 \\
\hline Protoperidinium sympholis & 2 \\
\hline Scrippsiella trochoidea & 2 \\
\hline Climacodium sp. & 1 \\
\hline Eucampia cornuta & 1 \\
\hline Fragilaria cf. construens & 1 \\
\hline Gomphonema sp. & 1 \\
\hline Plagiogramma sp. & 1 \\
\hline Pleurosigma sp. & 1 \\
\hline Dinophysis forthii & 1 \\
\hline Dinophysis hastata & 1 \\
\hline Gonyaulax spinifera & 1 \\
\hline Protoperidinium claudicans & 1 \\
\hline Protoperidinium conicum & 1 \\
\hline Protoperidinium crassipes & 1 \\
\hline Pyrocistis sp. & 1 \\
\hline
\end{tabular}

\section{Especies nocivas}

En el área de muestreo se identificaron tres especies relacionadas a la producción de toxinas: Alexandrium catenella (VPM), Dinophysis acuta y D. acuminata (VDM). Los tres taxa se presentaron en numerosas ocasiones, apareciendo en el 4,5\% de las muestras A. catenella, en un $25 \% D$. acuta, y en un $31,3 \% D$. acuminata.

\section{Alexandrium catenella}

Esta especie causante de intoxicaciones humanas en el extremo sur de Chile, apareció solamente en seis ocasiones, lo que representa el $4,5 \%$ de las muestras analizadas, siendo tres de baja importancia en Abundancia Relativa (A.R. $=1$ ), dos de mediana abundancia (A. R.= 2,5) y una muy importante, en la que se presentó en forma masiva (A. R.= 5) durante marzo de 1998. En el período 1992-1999, el Servicio de Salud Aysén ha registrado en esta zona 60 casos de intoxicación en personas y 6 fallecidos (Fernández, 1999).

Alexandrium catenella incrementó su abundancia y frecuencia de apariciones desde 1994 hasta 1998. La presencia de esta especie se relacionó con cambios importantes en la temperatura del agua, centrándose la mayoría de las apariciones en el rango de 11 a $14{ }^{\circ} \mathrm{C}$, observándose junto a otras especies de hábitat marino, también nombradas como acompañantes del género Dinophysis (Tabla 5).

\section{Tabla 5}

Taxa acompañantes de las especies del género Dinophysis. Taxa found with Dinophysis species.

\begin{tabular}{|l|}
\hline \multicolumn{1}{|c|}{ Diatomeas } \\
\hline Actinoptychus senarius \\
Chaetoceros curvisetus \\
Chaetoceros decipiens \\
Chaetoceros diadema \\
Coscinodiscus janischii \\
Detonula pumila \\
Eucampia cornuta \\
Lauderia annulata \\
Paralia sulcata \\
Guinardia delicatula \\
Thalassiossira cf. minuscula \\
\hline \multicolumn{1}{|c|}{ Dinoflagelados } \\
\hline Alexandrium catenella \\
Protoperidinium claudicans \\
Protoperidinium conicum \\
Protoperidinium crassipes \\
Protoperidinium depressum \\
Protoperidinium divergens \\
Protoperidinium oceanicum \\
Protoperidinium pedunculatum \\
Protoperidinium pentagonum \\
Protoperidinium punctulatum \\
Protoperidinium steinii \\
\hline Dictyocha fibula \\
Dictyocha speculum \\
\hline
\end{tabular}




\section{Dinophysis}

El género Dinophysis está representado en estas aguas por varias especies, entre las que se encuentran $D$. acuta y $D$. acuminata. Solamente la primera especie ha sido relacionada con intoxicaciones por VDM en Chile; sin embargo Taylor et al. (1995) atribuye la producción de toxinas a ambas.

Dinophysis acuta se presentó en 32 ocasiones durante el período de muestreo, variando su A. R. entre 1 y 4 . Los años más marcado por sus apariciones fueron 1994 y 1998, mientras que durante 1996 y 1997 prácticamente estuvo ausente, presentándose solamente una vez cada año (Fig. 11). Esta especie se encontró en el $25 \%$ de las muestras, y en todo el rango de temperatura registrado; sin embargo, el mayor número e intensidad ocurrió entre los 11 y $15^{\circ} \mathrm{C}$.

Dinophysis acuminata se observó en 40 ocasiones, esto es el $31,25 \%$ de las muestras analizadas, variando su
A. R. entre 1 y 4. Los años más marcados por su presencia fueron 1994 y 1998, siendo 1996 y 1997 los años que presentaron menor cantidad de apariciones, todas de baja intensidad (Fig. 12).

El rango de temperatura en que se presentaron los florecimientos más intensos de esta especie, fue entre $10,5^{\circ} \mathrm{C}$ y $15,5^{\circ} \mathrm{C}$.

Durante los tres primeros años D. acuta fue más numeroso que D. acuminata, pero desde 1996 esta relación se invierte, siendo esta última especie más abundante hasta 1998.

Phalacroma rotundatum, dinoflagelado heterótrofo relacionado al género Dinophysis (Hansen, 1991), solamente fue observada en 11 ocasiones, las que se centraron en los años 1994 y 1998, durante los cuales alcanzó valores muy altos de abundancia, normalmente junto a otras especies de dinoflagelados, especialmente del género Dinophysis.

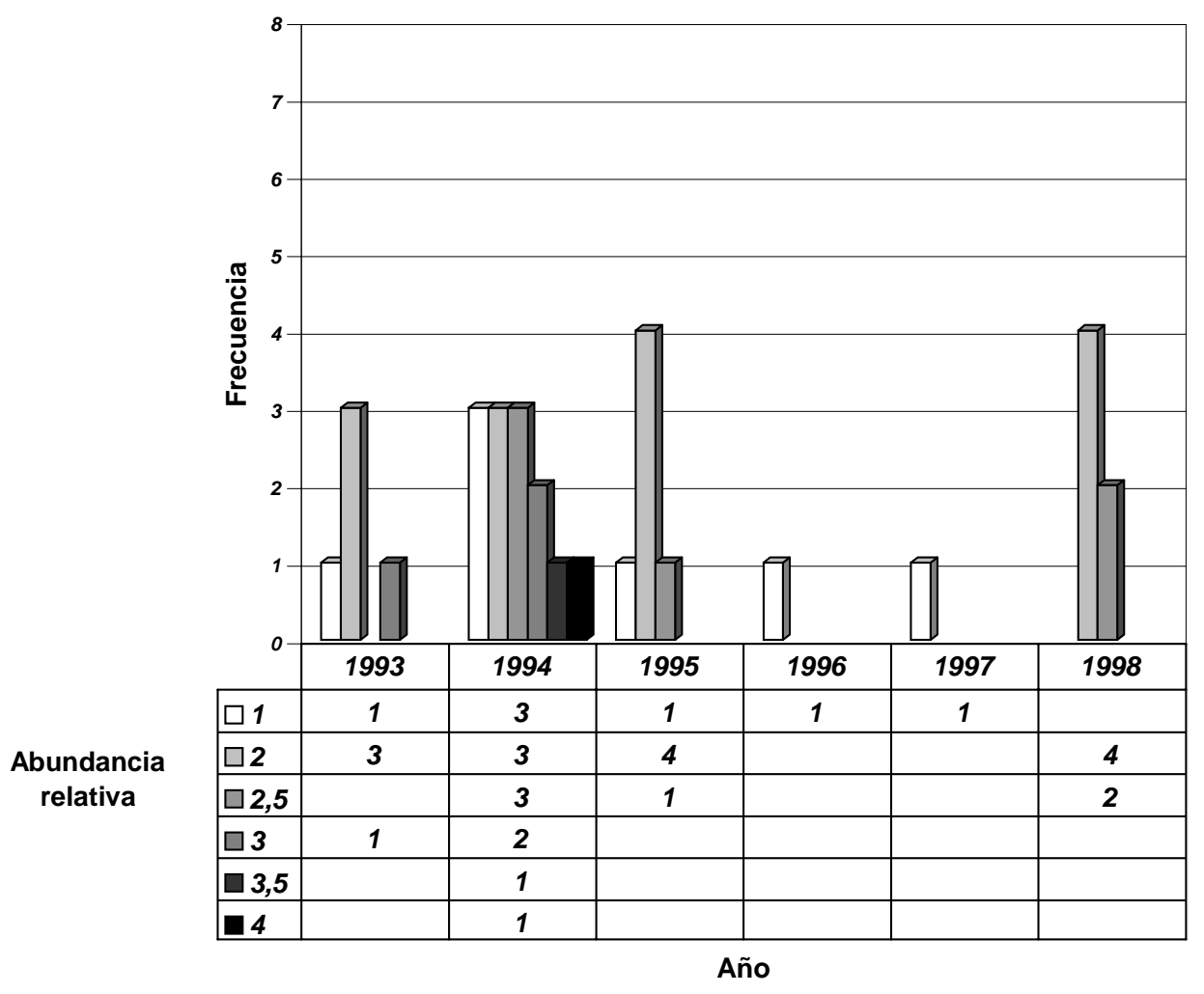

Figura 11

Abundancia relativa de Dinophysis acuta para cada año. Dinophysis acuta relative abundance for each year. 


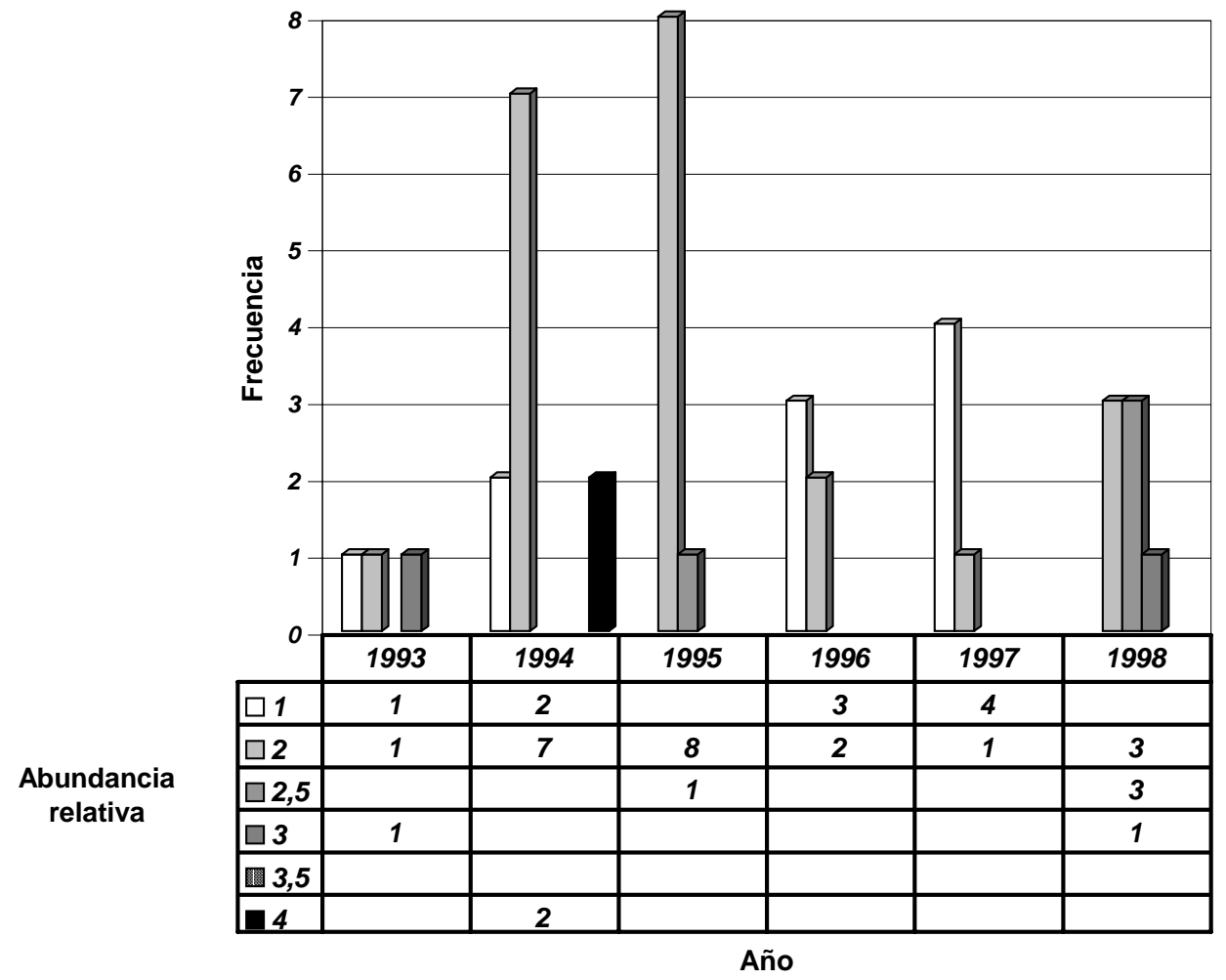

Figura 12

Abundancia relativa de Dinophysis acuminata para cada año. Dinophysis acuminata relative abundance for each year.

\section{Estacionalidad e historia de las Floraciones Algales Nocivas en Aysén}

Al sumar las abundancias estimadas (expresadas como número aproximado de células por gota) de las especies citadas como nocivas a la salmonicultura $y$ las relacionadas con la producción de toxinas, se puede observar que las proliferaciones de estos organismos ocurren durante los meses cálidos, principalmente entre diciembre y abril, concentrándose estas apariciones en el mes de febrero (Fig.13).

El primer florecimiento nocivo registrado en el período de estudio acontece en agosto de 1993, siendo causado por especies del género Dinophysis.

Durante 1994 se produjeron floraciones casi ininterrumpidas entre enero y julio, predominando en ellas las tres especies de Dinophysis encontradas en el fiordo. Cabe destacar la gran abundancia de D. acuta, especie relacionada en Chile con la presencia de VDM. Durante ese año se detectó el mayor florecimiento de especies nocivas, compuesto por $D$. acuta, $D$. acuminata y Phalacroma rotundatum, además de Pseudo-nitzschia cf. australis, la que puede causar problemas a los salmones en jaulas por sus largas cadenas bien silicificadas.

El año 1995 fue un año con baja aparición de especies tóxicas, aunque no estuvo libre de floraciones nocivas, especialmente para la salmonicultura, ya que desde diciembre de 1994 se registran altos números de Pseudo-nitzschia cf. seriata y $P$. delicatisima, repitiéndose esta última en febrero y en septiembre de 1995, junto a Rhizosolenia setigera.

Durante 1996 y 1997 los florecimientos de especies nocivas estuvieron prácticamente ausentes, registrándose solamente uno pequeño de $R$. setigera, en abril de 1996. En 1997 se observó la misma tendencia del año anterior, apareciendo pequeñas cantidades de Alexandrium catenella junto a Heterocapsa triquetra, en febrero. Durante abril, Chaetoceros convolutus se observó en cantidades moderadas. 

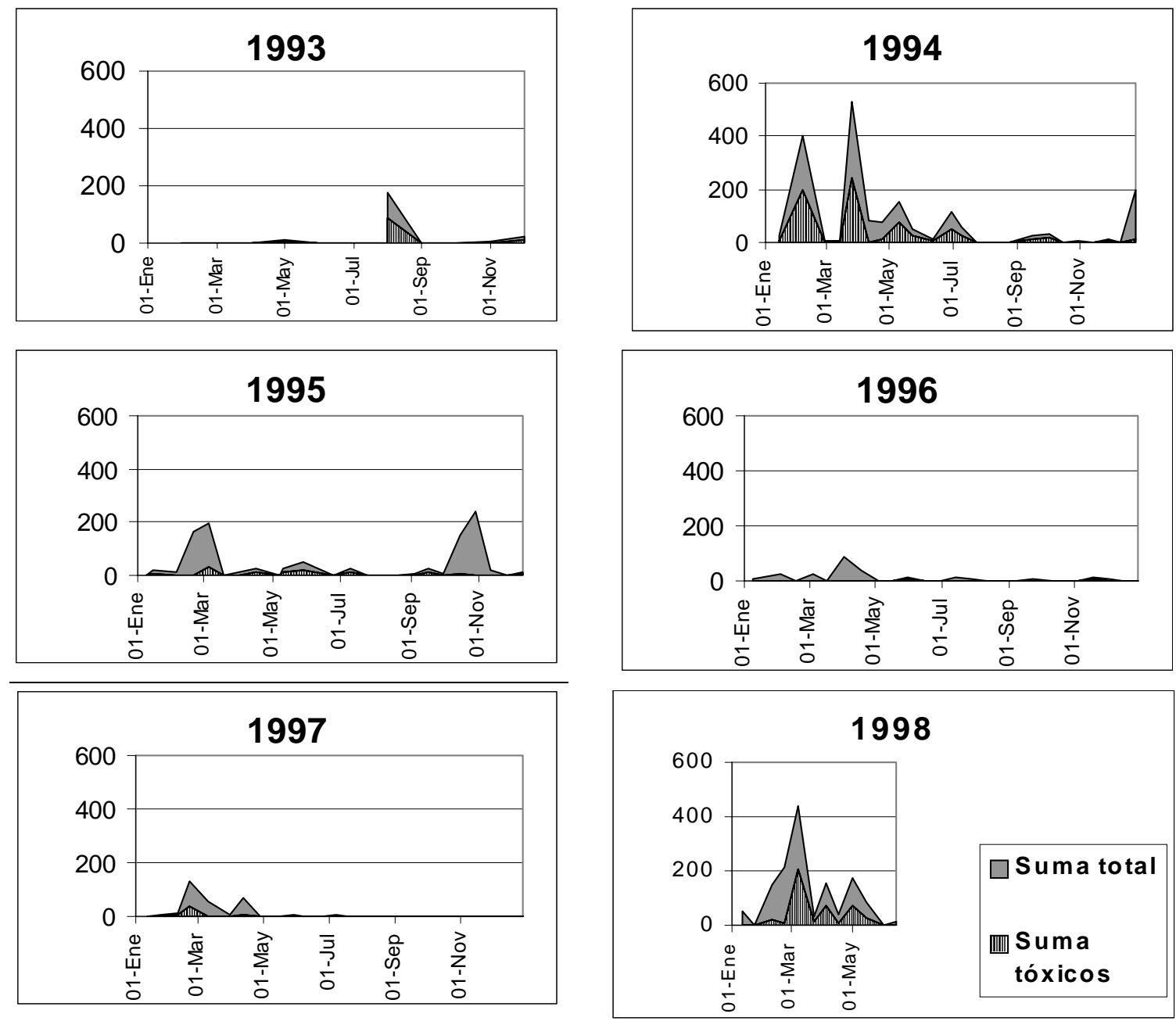

Figura 13

Comparación por año entre el número de células de especies nocivas totales y especies tóxicas. Annual comparison between total cell number for harmful species and toxic species.

El año 1998 es comparable a 1994, ya que presenta floraciones nocivas desde enero hasta mediados de año, compuestas por especies asociadas a toxinas, especialmente $A$. catenella y especies del género Dinophysis. Es destacable el caso de 1998, ya que presenta una gran floración de A. catenella ocurrida el 9 de marzo, la que coincide con un florecimiento masivo de esta especie en todo el sur de Chile durante ese mes, con extraordinaria abundancia de esta especie en las aguas del canal Moraleda, adyacente a la boca del seno Aysén (com. pers. C. Molinet).

Junto al florecimiento de A. catenella, el año 1998 también presentó apariciones importantes de especies de Pseudo-nitzschia, género que ha sido relacionado con intoxicaciones por Veneno Amnésico de Mariscos (VAM), en otros lugares del mundo.

\section{Aparición de especies nocivas y su relación con la temperatura}

Al comparar las apariciones de especies tóxicas de las muestras con la temperatura superficial del agua registrada, se observa que los altos valores alcanzados en 1994 y en 1998 coincidieron con períodos de temperaturas superiores al promedio, decreciendo en número e intensidad en 1995, año cercano al promedio de temperatura. Esto coincide con lo expuesto por Hallegraeff (1998), sin embargo, las especies nocivas no tóxicas aumentaron la intensidad de sus apariciones, 
destacándose los florecimientos de especies de los géneros Pseudo-nitzschia, Rhizosolenia y Chaetoceros.

Durante 1996 se registró Rhizosolenia setigera y Chaetoceros convolutus. Ese año fue similar a 1997 que, aunque cercano al promedio, puede considerarse de bajas temperaturas y prácticamente libre de especies tóxicas.

El año 1998 presentó temperaturas altas desde mediados de enero, las cuales alcanzan los mayores valores observados, lo que coincide con grandes florecimientos de especies relacionadas a toxicidad en el período analizado. Ese año también hubo registros importantes de especies del género Pseudo-nitzschia.
Este comportamiento relacionado a la temperatura, se pudo observar también al promediar los valores anuales de las especies nocivas, para obtener una visión global del problema (Fig. 14).

Las especies relacionadas a la producción de VPM y VDM, se presentaron en numerosas ocasiones en el área de muestreo, sin evidenciar un ciclo anual definido. Sin embargo, se estableció una relación entre la aparición de estas especies y la temperatura superficial del agua, presentándose los taxa productores de toxinas durante los meses cálidos, especialmente en los años con anomalía térmica positiva, mientras que las especies dañinas para la salmonicultura predominaron durante los años más fríos.

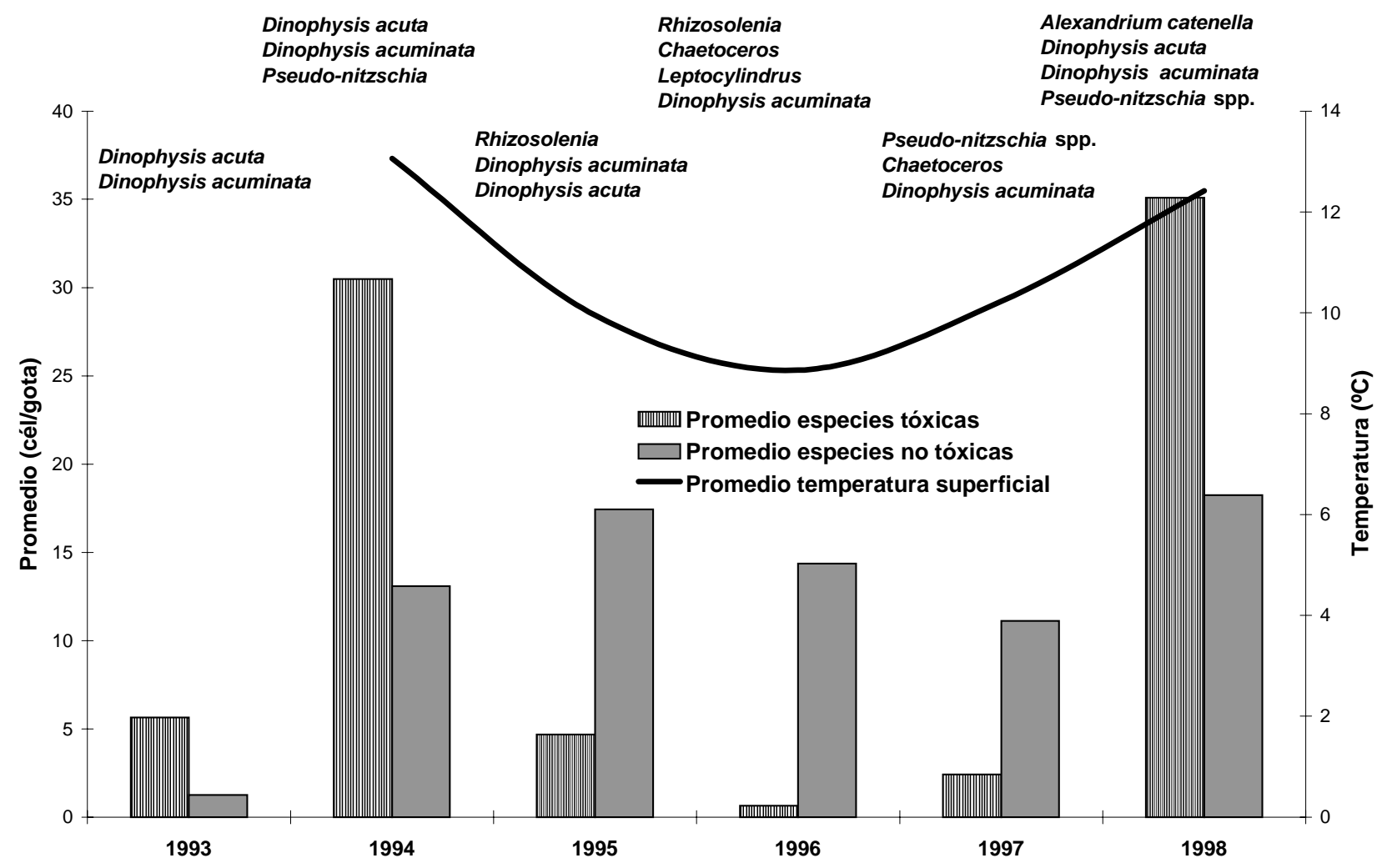

Año

Figura 14

Promedios anuales de temperatura, especies tóxicas y dañinas para la salmonicultura. Annual average values for temperature, harmful and toxic microalgae. 


\section{Especies acompañantes de los taxa relacionados a floraciones tóxicas}

Los taxa acompañantes de Dinophysis acuta y $D$. acuminata en sus florecimientos, fueron Actinoptychus senarius, Chaetoceros curvisetus, C. decipiens, C. diadema, Coscinodiscus janischii, Detonula pumila, Eucampia cornuta, Lauderia annulata, Paralia sulcata, Guinardia delicatula, Thalassiossira cf. minuscula, Skeletonema costatum, tanto en su morfotipo marino como en el de aguas de baja salinidad, Alexandrium catenella, especies de Protoperidinium de hábitat marino y los silicoflagelados Dictyocha fibula y D. speculum.

Estas especies corresponden a diferentes ambientes, distinguiéndose marinas y estuarinas, predominando las primeras sobre las segundas durante los florecimientos tóxicos. Además, se observó una mezcla de especies marinas y estuarinas, ante la presencia de plancteres nocivos para la salmonicultura.

Normalmente las especies de hábitat de agua de baja salinidad se encuentran ocupando entre el 50 y el $70 \%$ de la abundancia estimada, sin embargo, durante los florecimientos nocivos esta relación cambia abruptamente, favoreciéndose las especies de hábitat marino.

Los fitoplancteres acompañantes de las especies asociadas a fenómenos tóxicos fueron en su mayoría de origen marino nerítico, mientras que los taxa nocivos para la salmonicultura aparecieron junto a organismos de aguas estuarinas. Sin embargo, durante algunas oportunidades el género Dinophysis estuvo acompañado por diatomeas continentales, lo que indica su migración vertical desde el estrato de aguas marinas hacia la superficie, menos salina pero con mayor aporte de nutrientes y luz, coincidiendo con lo expuesto por Smayda (1997).

Las presencia masiva de especies dañinas a la salmonicultura como Chaetoceros convolutus y Rhizosolenia setigera, aparecieron acompañadas por las diatomeas Chaetoceros radicans, Ditylum brightwelli, Melosira pseudogranulata, Pseudo-nitzschia cf. australis, Synedra ulna, Stephanopyxis turris, Skeletonema costatum en su forma de aguas de baja salinidad y Thalassionema nitszchioides. Otros taxa presentes en estas muestras fueron los dinoflagelados Ceratium fusus var. seta y Protoperidinium obtusum, más el silicoflagelado Dictyocha speculum.

La segunda especie dañina no tóxica en importancia fue Rhizosolenia setigera, por el número e intensidad de sus apariciones, detectándose únicamente un florecimiento masivo en 1995, durante el cual estuvo acompañada por Licmophora sp., Melosira granulata, M. hustedti, Pseudo-nitzschia delicatissima y los dos morfotipos de Skeletonema costatum. Entre los dinoflagelados se incluye Dinophysis acuminata, Diplopsalis minor, Heterocapsa triquetra, Ceratium pentagonum var. robustum y varias especies del género Protoperidinium. Durante 1996 se detectó un florecimiento menor de Rhizosolenia setigera, asociado a la presencia de $R$. eriensis y otros taxa continentales y estuarinos.

Otro grupo de especies que puede ser considerado como nocivo a la salmonicultura y posiblemente como productor de VAM, es el formado por el género Pseudonitzschia, del cual se identificaron 3 especies. Este grupo se registró en aguas salobres, con marcada influencia de aguas cálidas marinas, acompañada por las diatomeas Proboscia alata f. gracillima, Rhizosolenia delicatula, $R$. Setigera, y las dos formas de Skeletonema costatum, con leve predominio del morfotipo de aguas marinas, Bacteriastrum sp, Cerataulina pelagica, Thalassionema nitszchioides, Eucampia cornuta, Ditylum brightwelli y gran variedad de especies del género Chaetoceros. Entre los dinoflagelados se incluye a Dinophysis acuta y D. acuminata.

\section{Conclusiones}

- Se identificaron 74 especies de diatomeas, 30 de dinoflagelados y 2 de silicoflagelados, con un total de 106 taxa.

- El análisis de las muestras permitió identificar nuevos taxa, destacando algunos de aguas continentales y oceánicos no descritos previamente para el área. Estos son: Actinoptychus senarius, Ceratoneis arcus, Melosira hustedti, Probocia alata f. gracillima, Dinophysis hastata, Protoperidinium crassipes, P. pentagonum, P. sympholis, Pyrophacus steinii y Dictyocha fibula.

- Algunas de las especies presentes en el fiordo como Cymatopleura sp., Cymbella sp., Diploneis sp., Gomphonema sp., son representantes de aguas continentales.

- El fitoplancton estuarino estuvo dominado por especies r-estratega, mientras que las K-estratega abundaban en las intrusiones marinas.

- Se detectaron en forma esporádica las especies Pyrophacus steinii, Pyrocystis sp. y Dictyocha fibula, cuyo hábitat son las aguas marinas cálidas, lo que indica que en algunas ocasiones las intrusiones marinas provienen de áreas alejadas de la costa, las 
que penetran al fiordo a través de la zona de canales e islas.

- Las diatomeas presentes pudieron ser divididas por el hábitat en que viven, utilizadas a la vez como indicadores de tipos de agua, permitiendo la identificación de intrusiones marinas dentro del fiordo Aysén por las especies observadas en las muestras.

- Los taxa estuarinos dominan durante todo el año, con abundancias estimadas mayores al 50\% del total, sin embargo son rápidamente desplazadas por las especies marinas, las que alcanzan hasta el 100\% durante las invasiones de agua desde el canal Moraleda.

- El fitoplancton del sector no sigue el patrón de sucesiones poblacionales, sino más bien se da una alternancia entre invasiones de especies de aguas continentales y marinas, al ambiente estuarino de la cabeza del fiordo.

- Las especies de hábitat estuarino Licmophora sp., Rhizosolenia eriensis, Synedra ulna, Skeletonema costatum y Thalassionema nitzschioides, siguen un ciclo anual en su abundancia estimada, con altos valores durante el verano y bajos durante el invierno.

- La abundancia estimada para los plancteres de los hábitats marino, continental y bentónico no siguió patrones establecidos, pero las mayores abundancias relativas ocurrieron durante la época de verano.

- Las especies ticopelágicas fueron muy escasas durante todo el período muestreado, mientras que las continentales tuvieron una mayor representación, lo que indica que el factor que incide mayormente en los cambios biológicos que suceden en la capa superficial de la cabeza del fiordo Aysén, se deben al aporte de agua dulce de los numerosos ríos que desembocan en el área.

- Skeletonema costatum en su morfotipo de aguas de baja salinidad fue la especie más representada, presentándose en el $63 \%$ de las muestras, apareciendo en floraciones muy intensas, asociadas con plancteres de aguas estuarinas y continentales.

- En el área de estudio se identificaron las especies Dinophysis acuta, D. acuminata y Alexandrium catenella, las que se asocian con toxicidad en mariscos, además, taxa de los géneros Rhizosolenia, Pseudo-nitzschia, Heterocapsa, Dictyocha y Chaetoceros, relacionados a daños en los cultivos de salmónidos.

- Las especies del género Dinophysis se registraron en cerca del $30 \%$ de las muestras. Alexandrium catenella se presentó en pocas ocasiones pero con un intenso florecimiento registrado en marzo de 1998.
- Los dinoflagelados asociados a toxinas aparecieron en mayor abundancia, en rangos de temperatura superficial del agua entre $10,5^{\circ} \mathrm{C}$ y $14,5^{\circ} \mathrm{C}$.

- Los taxa acompañantes de las especies asociados a toxinas fueron en su mayoría de hábitat marino nerítico, aunque en algunas ocasiones las especies de Dinophysis aparecieron junto a otros dinoflagelados marinos y diatomeas de aguas estuarinas.

- Las especies tóxicas aparecieron en mayor abundancia durante los años especificados como cálidos, mientras que los taxa asociados a daños en peces en cautiverio, fueron más abundantes en los años fríos.

- La temperatura superficial del agua presentó variaciones que marcaron dos estaciones bien diferenciadas: invierno y verano, sin estaciones intermedias.

- El promedio de temperatura para el período fue de $10,7^{\circ} \mathrm{C}$, presentándose los mayores valores en 1994 y 1998 , con $16,2^{\circ} \mathrm{C}$ y los menores en 1996 , con $5,2^{\circ} \mathrm{C}$.

- Los años 1994 y 1998 presentaron anomalías térmicas positivas, mientras que 1996 registró valores bajo el promedio estimado.

- En el área de estudio se presentaron variaciones de la temperatura del agua, las que se relacionaron con intrusiones de aguas marinas provenientes de canales adyacentes.

\section{Agradecimientos}

Expresamos nuestro reconocimiento al Almte. (R) Sr. Jorge Sepúlveda Ortíz y al Sr. Segundo Arza Torres, colonos de caleta Dagny, Nueva Hammerfest, XI Región, por el valioso apoyo brindado en la recolección de las muestras de fitoplancton.

\section{Literatura citada}

Avaria S. 1965. Diatomeas y silicoflagelados de la bahía de Valparaíso. Revista de Biología Marina, Valparaíso 12:61120.

Avaria S. 1970. Fitoplancton de la expedición del "Doña Berta” en la zona de Puerto Montt - Aysén. Revista de Biología Marina, Valparaíso 14(2):1-17.

Avaria S. 1993. Fitoplancton como indicador de El Niño. En Resúmenes de los trabajos presentados por los autores al Curso-Taller Internacional sobre indicadores biológicos del fenómeno El Niño en el Pacífico sudeste. Cali, Colombia. Proyecto PNUD (CPPS/COI) RLA/88/010 Vigilancia y Predicción del Fenómeno El Niño, p.12-16. 
Avaria S, D Cassis, P Muñoz y P Vera. 1997. Distribución del microfitoplancton marino en aguas interiores del sur de Chile en Octubre de 1995 (Crucero Cimar-Fiordo I). Ciencia y Tecnología del Mar 20:107-123.

Avaria S, I Jorquera, $P$ Muñoz y $P$ Vera. 1999a. Distribución del microfitoplancton marino en la zona de aguas interiores comprendida entre el Golfo de Penas y el Estrecho de Magallanes, Chile, en la primavera de 1996 (Crucero Cimar-Fiordo 2). Ciencia y Tecnología del Mar 22:81-110.

Avaria S, P Muñoz, C Cáceres y P Vera. $1999 b$. Variaciones en la composición y abundancia del microfitoplancton en el área oceánica, canal de Moraleda y boca de fiordos al norte y al sur de la constricción de Meninea. Resúmenes ampliados. Resultados Crucero CIMAR-Fiordo 4 :47-51.

Balech E. 1988. Los dinoflagelados del Atlántico sudoccidental. Publicaciones Especiales, Instituto Español de Oceanografía,1, 310p.

Cupp E. 1943. Marine Plankton Diatoms of the West Coast of North America. Bulletin of the Scripps Institution of Oceanography 5(1): 1-237.

Fernández R.D. 1999. Marea roja: monitoreo y vigilancia epidemiológica XI Región Aysén. Resumen Seminario Internacional de Marea Roja. Riesgos para la salud humana y el desarrollo de los países. 3-5 Agosto 1999, Puerto Varas, Chile. 1p.

Ferrario M, E Sar \& S Sala. 1995. Metodología básica para el estudio del fitoplancton con especial referencia a las diatomeas. En: Alveal K, ME Ferrario, EC Oliveira \& E Sar (Eds.). 1995. Manual de métodos ficológicos. Universidad de Concepción. Chile.

Guzmán L e I Campodonico. 1972. Fitoplancton de red de Puerto Edén (26 Marzo al 2 de Abril de 1971). Anales del Instituto de la Patagonia 3:209-220.

Hansen PJ. 1991. Dinophysis - a planktonic dinoflagelate genus which can act both as a prey and a predator of a ciliate. In Marine Progress Series 69:201-204.

Hallegraeff G. 1998. Concluding remarks on the autoecology of harmful algal blooms. In: Anderson D, A Cembella y G Hallegraeff (Eds.). Physiological Ecology of Harmful Algal Blooms. NATO ASI Series G: Ecological Sciences, vol 41. p.371-378.

Medina M. 1997. Estudio comparativo del fitoplancton del seno Aysén, XI región, y variables oceanográficas asociadas en cruceros de verano y otoño (1992). Tesis presentada al Instituto de Oceanología de la Universidad de Valparaíso, para optar al grado de Licenciado en Biología Marina.63pp. Anexos 1-3. (in litteris)

Montecino V. 1985. Fitoplancton estuarial y de aguas límnicas. Revista de Biología Marina, Valparaíso 21(1):199-210.
Muñoz P. 1985. Revisión taxonómica de los dinoflagelados de Chile. Revista de Biología Marina, Valparaíso 21(1):31-60.

Muñoz P y S Avaria. 1997. Fenómenos de marea roja y otras floraciones algales en Chile. Ciencia y Tecnología del Mar 20:175-192.

Muñoz P, S Avaria, H Sievers y R Prado. 1992. Presencia de dinoflagelados tóxicos del género Dinophysis en el seno Aysén, Chile. Revista de Biología Marina, Valparaíso 27(2):187-212.

Parra O, H González y M González. 1984. A comparision of epiphytic diatom assemblages attached to filamentous algae in lotic freshwater habitats of Chile. Gayana Botánica 41(1-2):85-118.

Pickard G. 1971. Some physical oceanographic features of inlets of Chile. Journal of the Fisheries Research Board of Canada 28(8):1077-1106.

Rivera P. 1968. Sinopsis de las diatomeas de la bahía de Concepción, Chile. Gayana Botánica 18.

Rivera P. 1974. Diatomeas de agua dulce de Concepción y alrededores (Chile). Gayana Botánica 28.

Rivera P. 1975. Diatomeas epífitas en Gracilaria verrucosa (Hudson) Papenfuss recolectada en la costa chilena. Gayana Botánica 25.

Rivera P. 1985. Diatomeas y silicoflagelados: investigaciones taxonómicas realizadas en Chile y problemas existentes. Revista de Biología Marina, Valparaíso 21(1):9-30.

Rivera P,O Parra, M González. 1973. Fitoplancton del estero Lenga, Chile. Gayana Botánica 23.

Rivera P, O Parra, M González, V Dellarossa y M Orellana. 1982. Manual taxonómico del fitoplancton de aguas continentales, con especial referencia al fitoplancton de Chile. Tomo IV Bacillariophyceae, 97 pp. Universidad de Concepción.

Romero O. 1994. Variación morfológica de Skeletonema costatum (Greville) Cleve (Bacillariophyceae) en el fiordo Aysén, Chile. Revista de Biología Marina, Valparaíso 29(1):1-21.

Sievers H y R Prado. 1994. Contraste de las características oceanográficas del seno Aysén, Chile, entre invierno y verano. Revista de Biología Marina, Valparaíso 29(2):167209.

Silva N, H Sievers y $\mathbf{R}$ Prado. 1995. Características oceanográficas y una proposición de circulación para algunos canales australes de Chile entre $41^{\circ} 20^{\prime} \mathrm{S}$ y $46^{\circ} 40^{\prime}$ S. Revista de Biología Marina, Valparaíso 30(2):207-254.

Silva N, D Guzmán y A Valdenegro. 1999. Balance de agua y sal para el seno Aysén, Chile. Resúmenes Ampliados Resultados Crucero CIMAR-FIORDO 4: 18-24. 
Smayda T. 1997. Harmful algal blooms: Their ecophysiology and general relevance to phytoplancton blooms in the sea. Limnology and Oceanography 42(5, part 2):1137-1153.

Taylor F, Y Fukuyo \& J Larsen. 1995. Taxonomy of Harmful Dinoflagellates. Hallegraeff G, B Anderson, A Cembella (Eds.) Manual on Harmful Marine Microalgae. IOC Manuals and Guides $n^{\mathrm{a}}$ 33. UNESCO. p.279-318.

Tomas C. 1997. Identifying Marine Phytoplankton, 858p. Academic Press, San Diego, California.
Uribe E. 1985. Indicadores biológicos en el fitoplancton marino. Revista de Biología Marina, Valparaíso 21(1):151-172.

Vera P, S Avaria y $\mathbf{P}$ Muñoz. 1996. Composición del fitoplancton de los fiordos adyacentes a Campos de Hielo Sur y su relación con algunos parámetros oceanográficos. Ciencia y Tecnología del Mar 19:73-92. 